Universidade de São PaUlo

Faculdade de Odontologia de Ribeirão Preto

DEPARTAMENTO DE CLÍNICA INFANTIL

\title{
Resistência ao Cisalhamento de Bráquetes Ortodônticos Cerâmicos Colados com Diferentes compósitos \\ E IRRADIADOS COM LASER DE $\mathrm{CO}_{2}$
}


UNIVERSIDADE de SÃo PAULO

Faculdade de Odontologia de Ribeirão Preto

Departamento de ClíniCA INFANTIL

\section{Resistência ao Cisalhamento de Bráquetes Ortodônticos \\ Cerâmicos Colados com Diferentes compósitos \\ E IRRADIADOS COM LASER DE $\mathrm{CO}_{2}$}

Dissertação apresentada ao Programa de Pósgraduação em Odontopediatria, área de concentração em Odontopediatria da Faculdade de Odontologia de Ribeirão Preto da Universidade de São Paulo, como requisito parcial para obtenção do título de Mestre em Ciências.

Aluna: Denise de Souza Matos

Orientador: Prof. Dr. Fábio Lourenço Romano 
AUTORIZO A REPRODUÇÃO E DIVULGAÇÃO TOTAL OU PARCIAL DESTE TRABALHO, POR QUALQUER MEIO CONVENCIONAL OU ELETRÔNICO, PARA FINS DE ESTUDO E PESQUISA, DESDE QUE CITADA A FONTE.

\section{Ficha CATALOgRÁfica}

Matos, Denise Souza

Resistência ao cisalhamento de bráquetes ortodônticos cerâmicos colados com diferentes compósitos e irradiados com laser de $\mathrm{CO}_{2}$. Ribeirão Preto, 2013

67 p. : il. ; $30 \mathrm{~cm}$

Dissertação de Mestrado apresentada à Faculdade de Odontologia de Ribeirão Preto/USP - Área de Concentração: Odontopediatria.

Orientador: Prof. Dr. Fábio Lourenço Romano

1. Bráquetes ortodônticos 2. Laser $\mathrm{CO}_{2}$ 3. Resistência ao cisalhamento

4. Ortodontia 
Matos DS. Resistência ao Cisalhamento de Bráquetes Ortodônticos Cerâmicos Colados com Diferentes compósitos e Irradiados com Laser de $\mathrm{Co}_{2}$

Dissertação apresentada ao Programa de Pósgraduação em Odontopediatria, área de concentração em Odontopediatria da Faculdade de Odontologia de Ribeirão Preto da Universidade de São Paulo, como requisito parcial para obtenção do título de Mestre em Ciências.

Data da defesa:

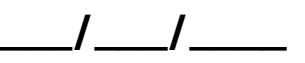

\section{Banca Examinadora}

Prof. Dr.

Instituição:

Julgamento: Assinatura:

Prof. Dr.

Instituição:

Julgamento: Assinatura:

Prof. Dr.

Instituição:

Julgamento: Assinatura: 
DADOS CURRICULARES

Denise de Souza Matos

Nascimento 24 de janeiro de 1987 - Patos de Minas/MG

Filiação Geraldo de Souza Magela

Diuza Geralda de Matos Souza

2005 - 2008 Graduação em Odontologia

Faculdade de Odontologia de Araraquara - UNESP

2011 - 2013 Especialização em Odontopediatria

Associação Odontológica de Ribeirão Preto - AORP

2011 - 2013 Mestrado em Ciências

Área de concentração: Odontopediatria

Faculdade de Odontologia de Ribeirão Preto - USP

Orientador: Prof. Dr. Fábio Lourenço Romano

Bolsa: CAPES 
Dedicatória 


\section{DedicatórIA}

À Deus, por ter me direcionado até este caminho e me dado força para atingir meu objetivo, sem ti nada seria possivel, agradeço por todos os momentos em que senti tua presença e tua influência em minha vida mesmo que em um primeiro momento não as tenha reconhecido, obrigada pelo presente que tem me dado todos os dias ao acordar e ter a certeza de que estou na direção certa.

À minha mãe Diuza, pelo carinho, amor, dedicação, confiança. Obrigada por ser meu porto onde posso retornar sempre que necessito para me sentir segura. Obrigada por apoiar minhas escolhas, por fazer com que tudo parecesse mais fácil com suas palavras de incentivo e por estar sempre presente, mesmo quando eu estive ausente. Com você aprendi que o que realmente importa são as pessoas com quem podemos contar sempre, e que nossa família é o bem mais precioso que temos.

Ao meu pai Geraldo, meu incentivo para seguir a Odontologia, meu exemplo e meu herói. Com você aprendi os valores mais importantes, honestidade e sinceridade. Obrigada pela compreensão, apoio e confiança, por nunca transmitir seus problemas e por sempre ter ouvidos para os meus. Obrigada por me passar a calma que muitas vezes me faltava com uma simples conversa ao telefone com sua voz serena. Por me conhecer tão bem e mesmo assim aceitar meus defeitos.

A vocês pai e mãe,

dedico toda minha vida, todas as minhas conquistas e todas as minhas vitórias!

Aos meus irmãos, Viviane, Alexandre e Rosălia, pela companhia, pelas risadas, pela cumplicidade, vocês são meus verdadeiros amigos com quem sei que posso sempre contar, amo vocês!

"O verdadeiro amor nunca se desgasta. Quanto mais se dá mais se tem." Antoine de Saint-Exupéry 
Agradecimento Especial 


\section{Agradecimento Especial}

Ao meu orientador, Prof. Dr. Fábio Lourenço Romano, a quem admiro e respeito como pesquisador, professor e principalmente como pessoa. Obrigada pela orientação e convivência, por me ensinar que os bons resultados são fruto de muito esforço e dedicação. Por ouvir minhas ideias e respeitar meus pontos de vista, por me ensinar a gostar e a enxergar com outros olhos a ortodontia. A você professor, meu mais sincero obrigada.

"O saber a gente aprende com os mestres e os livros. A sabedoria se aprende com a vida e com os humildes."

Cora Coralina 
Agradecimentos

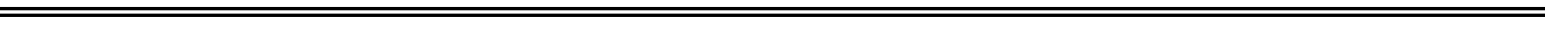




\section{AgradeCIMENTOS}

À Profa. Dra. Maria Cristina Borsatto pela ajuda e presença constante durante a fase experimental do projeto, obrigada por contagiar o ambiente com sua presença e sua risada gostosa.

Ao Prof. Dr. Rodrigo Galo, pelas orientações, pela disponibilidade, pela companhia no laboratório, obrigada pela dedicação a este trabalho.

À Profa. Dra. Regina Guenka Palma Dibb, pela atenção.

Á secretāria do curso de especialização em Ortodontia da FUNORP Rosemary Alves, obrigada pela atenção dedicada a mim e a este trabalho, você é uma pessoa especial.

Aos Professores do departamento de Clínica Infantil, Adilson Thomasin, Aldevina C. de Freitas, Alexandra Mussolino de Queiroz, Andiara De Rossi Daldegan, José Tarcísio Lima Ferreira, Kranya Victoria Díaz Serrano, Léa Assed Bezerra da Silva, Maria Bernadete Sasso Stuani, Maria da Conceição Pereira Saraiva, Mírian A. N. Matsumoto, Paulo Nelson Filho, Raquel Assed Bezerra da Silva, Sada Assed, por se mostrarem sempre disponiveis, por repassarem seus conhecimentos e por serem um exemplo de excelência no que fazem.

Aos Funcionários: Carmo Eurípedes Terra Barreto, Carolina Paes Torres Mantovani, Fătima Aparecida Jacinto Daniel, Filomena Leli Placciti, Francisco Wanderley Garcia de Paula e Silva, Marco Antônio do Santos, Marilia Pacífico Lucisano, Matheus Morelli Zanela, Nilza Letícia Magalhães, Renata Aparecida Fernandes, Ditinha Rodrigues, Vera Scandelai, Sr. José, Isabel Sola e Regiane Moi.

À secretária da pós-graduação Micheli Cristina Leite Rovanholo, por estar sempre disposta a esclarecer nossas dúvidas e nos ajudar em qualquer situação. Obrigada!

Aos pós-graduandos do Departamento de Clínica Infantil, em especial: Bărbara Jarreta, Camila Scatena, Cinntia Guimarães Almeida, Danielly Cunha Araújo, Driely Barreiros, Fernanda Regina Ribeiro, Giselle Leite Carbonaro, Késsia Mesquita, Larissa Nogueira, Letícia Bignardi, Marina Sena, Marta Contente, Maya Arnez, Rodrigo Valêrio, 
Silvana Polizeli, Talita Pereira Prates, Eduardo Pioltine, pela maravilhosa companhia nos estudos.

Às amigas: Carol Fumes, Priscila Romualdo, Katharina Morant, Mariana Alencar, Daniele Lucca, muito mais que amigas. Obrigada pelo privilégio de ter o convívio de vocês nesses dois anos, nossas conversas, reuniões, almoços, serão sempre lembrados com muito carinho.

Às minhas amigas da graduação: Juliana Valente, Carolini Satiko, Ana Elisa Moya, Cristina Pavan, Emely Aveiro, Joana Antonelli, Elaine Machado, Margareth da Mata, Ludmilla Faria, amizades que levo para a vida toda.

Aos meus cunhados, Kleber Moreira, amigo e irmão, e Flávia Teixeira, pelo apoio.

À Sabrina Mota, amiga desde sempre e em qualquer situação, obrigada por fazer parte desta e de muitas outras conquistas.

Aos meus tios José André, Lourdinha e Alcídia, pela preocupação e torcida.

Aos meus pais, Geraldo e Diuza, e meus irmãos Viviane, Alexandre e Rosălia, sem os quais nada seria possivel, a vocês meu mais sincero agradecimento.

À Universidade de São Paulo.

À Faculdade de Odontologia de Ribeirão Preto da Universidade de São Paulo, na pessoa do atual diretor Valdemar Mallet da Rocha Barros e vice-diretora Léa Assed Bezerra da Silva.

$$
\text { À Capes. }
$$

À FAPESP pelo apoio financeiro, possibilitando a realização deste estudo.

"Tudo que um sonho precisa para ser realizado é de alguém que acredite que ele possa ser realizado." Roberto Shinyashiki 
Resumo = 


\section{Resumo}

Matos, DS. Resistência ao cisalhamento de bráquetes ortodônticos cerâmicos colados com diferentes compósitos e irradiados com laser de $\mathrm{CO}_{2}$ [dissertação]. Ribeirão Preto: FORP-USP, 2013.

O objetivo do trabalho foi avaliar a resistência ao cisalhamento de bráquetes ortodônticos cerâmicos com base de retenção química e mecânica, colados com diferentes compósitos e irradiados com laser de $\mathrm{CO}_{2}$. Foram utilizados 120 pré-molares humanos hígidos, suas coroas foram incluídas em resina acrílica e as faces vestibulares planificadas e polidas com lixas d'água até exposição de $5 \mathrm{~mm}$ esmalte. Posteriormente, as raízes dos dentes foram incluídas em tubos de PVC também com resina acrílica de forma que a face vestibular ficasse perpendicular à base do tubo. Os 120 corpos de prova foram divididos em 8 grupos $(n=15)$, sendo 2 controles e 6 experimentais. Nos grupos 1 e 2 (controles) o compósito utilizado para colagem foi o Transbond $\mathrm{XT}$, sendo que no grupo 1 foi colado o bráquete cerâmico Mystique (retenção mecânica) e no grupo 2 o bráquete cerâmico Fascination (retenção química). Nos grupos experimentais 3, 4 e 5 foi colado o bráquete Mystique com os compósitos Transbond XT, Concise e Z250, respectivamente. Nos grupos 6, 7 e 8 foi colado o bráquete Fascination com os mesmos compósitos dos grupos 3, 4 e 5, na mesma sequência. Nos grupos experimentais, após a colagem, os bráquetes foram irradiados com laser de $\mathrm{CO}_{2}$ com $10 \mathrm{~W}$ de potência por 3 segundos e pulso de 0,01 segundo. Imediatamente após a irradiação foi realizado o teste de resistência ao cisalhamento da colagem em máquina universal de ensaios mecânicos (Emic DL 500) à velocidade de $0,5 \mathrm{~mm} /$ minuto. Após o teste, as superfícies avaliadas por meio do Índice de Remanescente Adesivo (IRA) e submetidas à Microscopia Eletrônica de Varredura (MEV) para investigação de eventuais fraturas. Os dados de resistência ao cisalhamento foram submetidos à Análise de Variância ANOVA e posteriormente teste de Tukey. O teste de Mann-Whitney foi utilizado para a avaliação do IRA. Os resultados mostraram que os grupos experimentais apresentaram valores de resistência ao cisalhamento menores quando comparados aos controle $(p<0,05)$. 0 bráquete Mystique (retenção mecânica) apresentou valores maiores de resistência ao cisalhamento e o compósito Z 250 foi o que apresentou menor força de adesão após irradiação com laser de $\mathrm{CO}_{2}$. Os grupos 5 e 8 foram os que apresentaram maior média do IRA e para todas as superfícies avaliadas o modo de fratura mais prevalente foi a fratura adesiva . Concluiu-se que o laser de $\mathrm{CO}_{2}$ foi eficaz como auxiliar na descolagem de bráquetes cerâmicos de retenção química e mecânica.

Palavras-chave: Bráquetes ortodônticos, laser $\mathrm{CO}_{2}$, resistência ao cisalhamento, ortodontia. 


\section{Abstract}




\begin{abstract}
Matos, DS. Shear strength of ceramic orthodontic brackets bonded with different composites and irradiated with $\mathrm{CO} 2$ laser [dissertation]. Ribeirao Preto: FORP-USP, 2013.
\end{abstract}

The objective of this study was to evaluate the shear strength of the ceramic orthodontic brackets based in chemical and mechanical restraint, bonded with different composites and irradiated with $\mathrm{CO} 2$ laser was evaluated. Healthy human premolars (120) were used and their crowns were embedded in acrylic resin and the buccal surfaces flattened and polished with sandpaper until exposure of $5 \mathrm{~mm}$ of enamel. Subsequently, the roots of the teeth were included in PVC pipes also with acrylic resin so that the labial surface was perpendicular to the base of the pipe. The 120 samples were divided into 8 groups ( $n=15), 2$ being the control groups and 6, the experimental groups. In groups 1 and 2 (controls) the composite used for bonding was Transbond XT. Group 1 was glued to the ceramic bracket Mystique (by mechanical retention) and the group 2, with ceramic bracket Fascination (by chemical restraint). In the experimental groups 3, 4 and 5 Mystique brackets were glued with Transbond XT, Concise and Z250, respectively. In groups 6, 7 and 8 the Fascination bracket were glued with the same composites of groups 3,4 and 5 and in the same sequence. In the experimental groups, after bonding, the brackets were irradiated with $\mathrm{CO} 2$ laser with $10 \mathrm{~W}$ of power for 3 seconds and per pulse 0.01 seconds. Immediately after irradiation shear strength tests were performed on shear bonding with mechanical universal testing machines (Emic DL 500) at a speed of $0.5 \mathrm{~mm} /$ minute. After testing, the surfaces were evaluated using the Adhesive Remnant Index (ARI) and submitted to scanning electron microscopy (SEM) to investigate possible fractures. The shear strength data were subjected to analysis of variance with ANOVA and Tukey test later. The Mann-Whitney test was used to evaluate the ARI. The results showed that experimental groups showed lower shear strength values, comparing to the control groups ( $p<0.05$ ). The bracket Mystique (mechanical retention) showed higher shear strength values and the Z 250 composite showed the lowest adhesion strength after irradiation with $\mathrm{CO} 2$ laser. Groups 5 and 8 presented the highest average of IRA and for all the surfaces that were evaluated the most prevalent fracture mode was the adhesive one. It was concluded that the $\mathrm{CO} 2$ laser was effective as an aid in bracket debonding of ceramic with chemical and mechanical retention.

Keywords: Orthodontic Brackets, CO2 laser, shear strength, orthodontics. 
Lista de $F_{\text {iguras }}$ 


\section{Lista de Figuras}

Figura 1- Pré-molar humano (vista vestibular e lateral) .............................. 34

Figura 2- $\quad$ Corpo de prova com a face vestibular pressionada sobre a placa de vidro.

Figura 3- $\quad$ A - Politriz utilizada para lixar os corpos de prova; B - Corpo de prova na politriz.

Figura 4- Corpo de prova com a raiz incluída em tubo de PVC contendo resina acrílica.

Figura 5- Esquadro de vidro apoiado no troquel e no dente para verificar o posicionamento

Figura 6- $\quad$ A - Bráquete Fascination (vista frontal); B - Base de retenção química; C - Bráquete Mystique (vista frontal); D - Base de retenção mecânica.

Figura 7- Profilaxia da superfície.

Figura 8- Condicionamento ácido do esmalte.

Figura 9- $\quad$ A - Corpo de prova após a colagem do bráquete Mystique; B - Corpo de prova após colagem do bráquete Fascination.

Figura 10- Ensaio de resistência ao cisalhamento.

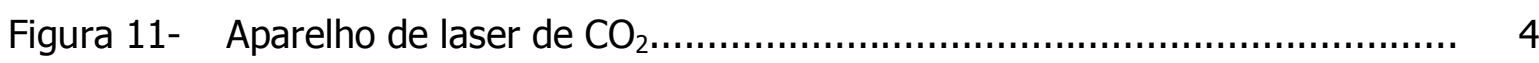

Figura 12- Irradiação do laser e ensaio de resistência ao cisalhamento................... 41

Figura 13- Imagem ilustrativa da superfície vestibular dos corpos de prova após a descolagem. A - IRA $0 ;$ B - IRA 1; C - IRA 2 e D - IRA 3

Figura 14- Fluxograma da parte metodológica.

Figura 15- Escores do Índice de Remanescente Adesivo (IRA) encontrado nos grupos.

Figura 16- Tipos de Fratura. A - Fratura Adesiva; B - Fratura Coesiva Resina; C - Fratura Coesiva Esmalte; D - Fratura Mista Coesiva Resina/Adesiva; E - Fratura Mista Coesiva Esmalte/Adesiva; F - Fratura Mista Coesiva Resina/Coesiva Esmalte. EH - Esmalte Hígido. C - Compósito. FE - Fratura de Esmalte. 
Lista de Tabelas 


\section{Lista de TABeLAS}

Tabela 1- Informações relativas aos materiais utilizados no estudo...................... 37

Tabela 2- Grupos controles e experimentais............................................... 38

Tabela 3- Valores médios de resistência ao cisalhamento (MPa), desvio padrão (DP) e comparação estatística.......................................................... 46

Tabela 4- Resultados do teste de Tukey para comparação entre os

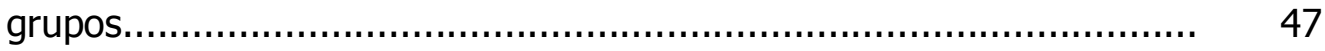

Tabela 5- Resultados médios do IRA.......................................................... 47

Tabela 6- Tipos de fraturas encontradas nos grupos......................................... 49 
Sumário 


\section{SUMÁRIO}

INTRODUÇÃO

PROPOSIÇÃO

MATERIAL E MÉTODOS

RESULTADOS

DISCUSSÃO

CONCLUSÃO

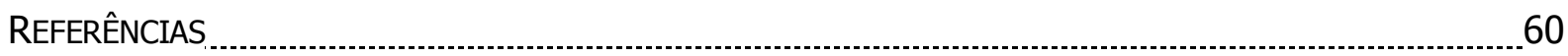

ANEXO 
Introdução 


\section{INTRODUÇÃO}

O número de pacientes adultos que buscam tratamento ortodôntico tem aumentado significativamente, com esta procura a utilização de bráquetes cerâmicos também cresceu de forma semelhante (Azzeh e Feldon, 2003). O aparelho com bráquetes metálicos, alternativa utilizada por longo período, vem sendo amplamente discutida na literatura tanto com relação a suas vantagens e desvantagens de uso como em relação ao prejuízo estético causado ao paciente que se submete ao tratamento ortodôntico (Azzeh e Feldon, 2003; Jena et al., 2007). Para contornar tal preocupação surgiram novas alternativas: bráquetes metálicos menores, aparelhos estéticos e ortodontia lingual. Esta última opção devido às dificuldades de manipulação pelo ortodontista, de higienização pelo paciente e desconforto, deve ser utilizada em casos específicos (Jena et al., 2007).

Os bráquetes chamados "estéticos" foram introduzidos pela primeira vez na Ortodontia em 1965 por Newman. Tratavam-se de acessórios de policarbonato e traziam consigo algumas desvantagens como a pouca estabilidade dimensional, durabilidade reduzida, embebição, alteração de cor o que gerava problemas estéticos, menor torque e maior deformação quando comparados aos metálicos. Hoje, a composição original dos bráquetes de policarbonato foi modificada pela adição de partículas de cerâmica e vidro com o objetivo de diminuir os problemas citados. No entanto, ainda apresentam inconvenientes na sua utilização sendo indicados para casos específicos como, por exemplo, em tratamentos de curta duração (Maltagliati et al., 2006).

Na década de 1970, surgiram os primeiros bráquetes cerâmicos com a finalidade de substituir os bráquetes de policarbonato (Russel, 2005; Jena et al., 2007). A cerâmica é uma classe ampla constituída por diversos materiais como vidro, argila, pedras preciosas e óxidos metálicos. A base da fabricação dos bráquetes cerâmicos é o óxido de alumínio $\left(\mathrm{AL}_{2} \mathrm{O}_{3}\right)$ que possui alta dureza, resistência a altas temperaturas, resistência a degradabilidade química e friabilidade (Azzeh e Feldon, 2003; Russell, 2005; Maltagliati et al., 2006; Jena et al., 2007) .

Existem dois tipos de bráquetes cerâmicos que diferem pela forma de fabricação: monocristalinos e policristalinos. Bráquetes cerâmicos monocristalinos são obtidos por meio do aquecimento de massa de óxido de alumínio que se funde a alta temperatura $\left(2100^{\circ} \mathrm{C}\right)$ resultando em única estrutura que é resfriada vagarosamente para permitir cristalização controlada. Este processo de fabricação confere menor incorporação de impurezas e imperfeições, menor radiopacidade e melhor estética. Outras características desses bráquetes são a maior resistência à tensão que é consequência da menor incorporação de impurezas durante a fabricação e o alto custo, pois cada bráquete é produzido individualmente (Karamouzos et al., 1997; Azzeh e Feldon, 2003; Russell, 2005; Maltagliati et al., 2006; Jena et al., 2007). 
Os bráquetes cerâmicos policristalinos são constituídos da mistura de cristais de óxido de alumínio fusionados a altas temperaturas pelo processo de sinterização. Este processo de fabricação permite a obtenção de vários bráquetes simultaneamente, sendo necessário tratamento térmico após o processo de sinterização para remoção das imperfeições superficiais que ocorreram durante a confecção e corte das peças. Por ser de fabricação mais simples, é de menor custo, e são os mais comumente utilizados na prática clínica. No entanto, devido ao seu processo de fabricação, ocorre maior incorporação de impurezas fazendo com que os bráquetes policristalinos sejam mais opacos quando comparados aos monocristalinos (Karamouzos et al., 1997; Azzeh e Feldon, 2003; Russell, 2005; Maltagliati et al., 2006; Jena et al., 2007).

Pesquisas avaliaram ambos materiais por meio de Microscopia Eletrônica de Varredura (MEV) e mostraram que bráquetes cerâmicos policristalinos apresentam ranhuras e poros em sua superfície, assim como, imperfeições que podem influenciar no desempenho do material e diminuir sua resistência (Kusy, 1988; Viazis et al., 1993).

Por ser a cerâmica um material inerte, a adesão do bráquete cerâmico sem meios de retenção ao esmalte dental torna-se impossível. Com o advento da técnica de condicionamento ácido criada por Buonocore em 1955, a utilização de compósitos para colagem de bráquetes diretamente ao esmalte dentário trouxe evolução para a Ortodontia. Assim como para a colagem de bráquetes metálicos, para a colagem de bráquetes cerâmicos são necessários meios de retenção adicionais na base do bráquete para que se tenha adesão entre o acessório, o compósito e o esmalte dentário. Essa adesão pode ser proporcionada de duas maneira: retenção mecânica e química (Karamouzos et al., 1997; Azzeh e Feldon, 2003; Maltagliati et al., 2006; Jena et al., 2007).

A retenção mecânica ocorre pela criação de microretenções como sulcos e ranhuras na base do bráquete que promovem embricamento mecânico entre o bráquete e o compósito. A retenção química é realizada pela adição de camada de silano na base do bráquete que atua como mediador químico entre o compósito e a base do bráquete e promove a união. Pesquisas mostram que a retenção química é responsável por força de união maior quando comparada ao meio de retenção mecânico (Karamouzos et al., 1997; Wang et al. 1997; Azzeh e Feldon, 2003; Russel, 2005; Maltagliati et al., 2006; Jena et al., 2007).

As propriedades físicas da cerâmica são resultado de sua composição atômica, além das ligações iônicas e covalentes existentes que conferem ao material dureza, alta resistência à tensão, baixa resistência à fratura e resistência à fricção (Karamouzos et al., 1997; Maltagliati et al., 2006; Jena et al., 2007). 
A dureza é uma propriedade física muito importante. Os bráquetes cerâmicos apresentam dureza muito superior aos metálicos. Devido a esta propriedade o contato oclusal entre o dente antagonista e o bráquete cerâmico é preocupação constante do ortodontista (Karamouzos et al., 1997; Maltagliati et al., 2006; Jena et al., 2007).

A alta resistência à tensão se deve a baixa ductibilidade e alto módulo de elasticidade da cerâmica. A ductibilidade é a capacidade do material se deformar até o momento de sua fratura. A cerâmica tem baixa capacidade de se deformar sob estresse. $\mathrm{O}$ módulo de elasticidade é a relação entre tensão e deformação de materiais sólidos, portanto, é necessária grande tensão para pequena deformação do bráquete cerâmico, o que acarreta fraturas em sua estrutura. Quando submetido à força de tração, a baixa capacidade de se deformar e a alta rigidez da cerâmica faz com que o ponto máximo da curva tensãodeformação do material se dê em níveis elevados (Karamouzos et al., 1997; Maltagliati et al., 2006; Jena et al., 2007). Quando comparados aos bráquetes metálicos, bráquetes cerâmicos se deformam menos de $1 \%$ antes da fratura, enquanto os metálicos cerca de $20 \%$ (Scott-Jr, 1988; Swartz, 1988; Jena et al., 2007).

A baixa resistência à fratura também se deve as características de ductibilidade e elasticidade do material. Essas características tem especial importância no momento da descolagem de bráquetes cerâmicos onde a ocorrência de fratura é comum e indesejada. A incorporação de impurezas e imperfeições durante a fabricação dos bráquetes cerâmicos policristalinos conferem a este grupo menor resistência à fratura quando comparado a bráquetes monocristalinos (Karamouzos et al., 1997; Maltagliati et al., 2006; Jena et al., 2007).

Bráquetes cerâmicos tem maior coeficiente de atrito quando comparado aos metálicos, uma vez que bráquetes metálicos e fios ortodônticos são fabricados do mesmo material. A resistência à fricção também é maior em bráquetes cerâmicos policristalinos devido a sua superfície ser mais áspera e porosa. Para solucionar tal problema é indicado o uso de bráquetes com canaletas (slot) revestidos de metal (aço inoxidável, ouro) ou tratamento especial conferindo grande lisura superficial (Karamouzos et al., 1997; Maltagliati et al., 2006; Jena et al., 2007).

Para a fixação de bráquetes metálicos e cerâmicos ao esmalte, os materiais de escolha são os compósitos. Os compósitos odontológicos contém três componentes estruturais que são conhecidos como matriz, carga e agente de união. A matriz em sua maioria é composta de mistura de monômeros dimetacrilatos aromáticos e/ou alifáticos, como o Bis-GMA, o trietilenoglicol dimetacrilato (TEGDMA) e o uretano dimetacrilato (UDMA). O Bis-GMA, o TEGDMA e o UDMA, são os responsáveis pela formação da estrutura 
de polímero com grande número de ligações cruzadas existentes nos compósitos (Pascotto et al., 2002; Anusavice, 2005; Chevitarese e Ruellas, 2005).

A incorporação de partículas de carga tem o objetivo de melhorar as propriedades dos compósitos, fortalecendo-os e diminuindo a quantidade de matriz. Geralmente são constituídas de quartzo ou vidro que passam por processo de moagem e produzem partículas de tamanho variados. A incorporação de metais pesados como bário $(\mathrm{Ba})$, estrôncio (Sr) e zircônio ( $\mathrm{Zr}$ ) também é usada para conferir radiopacidade ao compósito (Pascotto et al., 2002; Anusavice, 2005; Chevitarese e Ruellas, 2005).

Para que as partículas de carga tenham ação positiva sobre a matriz é essencial que elas estejam unidas de maneira satisfatória, caso contrário a adição de partículas de carga à matriz sem que haja união efetiva pode além de promover o reforço, também enfraquecer o material. A união entre essas duas fases do compósito ocorre por meio da ação do agente de união que normalmente são compostos de grupamentos metacrilatos organosilânicos que formam ligações covalentes com os compósitos quando estes são polimerizados, completando assim o processo de união (Pascotto et al., 2002; Anusavice, 2005; Chevitarese e Ruellas, 2005).

A classificação dos compósitos, normalmente é realizada de acordo com o tamanho médio das partículas de carga e sua distribuição (Pascotto et al., 2002; Anusavice, 2005). Os compósitos utilizados para colagem de bráquetes não diferem muito dos odontológicos usados para restaurações. Talvez por isso, seja comum entre os profissionais da área a utilização de compósitos destinados à restauração serem utilizados para colagem de bráquetes ortodônticos (Vargas, 1996; Pascotto et al., 2002; Chevitarese e Ruellas, 2005).

Para colagem de bráquetes ortodônticos existem materiais químio e fotoativados, com maior ou menor incorporação de partículas de carga que conferem ao material maior ou menor viscosidade, e que geralmente atendem bem a necessidade dos profissionais. $O$ ideal é que o cirurgião-dentista encontre o material mais adequado para sua habilidade de trabalhar. Especialmente para colagem de bráquetes cerâmicos, deve-se levar em consideração a escolha criteriosa do material, tendo em vista a dificuldade no momento da descolagem. Portanto, de acordo com a escolha do método de descolagem pode-se optar por um sistema adesivo que facilite tal procedimento, ou seja, com menor poder de adesão (Vargas, 1996; Pascotto et al., 2002; Chevitarese e Ruellas, 2005).

Sabe-se que, na cavidade bucal os compósitos odontológicos são submetidos constantemente à pequena variação de temperatura, portanto, é necessário que tais materiais sejam resistentes a essa alteração para que não haja mudança em suas propriedades físicas e estruturais que possam prejudicar o tratamento (Bishara et al., 1988). 
Quando submetidos a altas temperaturas, modificações estruturais são observadas, sendo que diferentes comportamentos entre os materiais podem ser explicados pelas suas composições (Rueggeberg e Lockwood, 1990; 1992).

Existe correlação direta entre o conteúdo de carga e matriz orgânica de um material e a resposta à variação de temperatura. Compósitos com grande quantidade de carga tendem a sofrer alterações quando submetidos a temperaturas mais altas, no entanto, a medida que o teor de matriz orgânica diminui, a temperatura de amolecimento dos compósitos também diminui, uma vez que o conteúdo orgânico é um bom isolante (Rueggeberg e Lockwood, 1990 e 1992).

A polpa dental humana também sofre grande influência da temperatura. Segundo Zach e Cohen (1965) a polpa pode suportar variação de até 5,5². Acima disto, os odontoblastos começam a sofrer alterações podendo levar inclusive à necrose pulpar. Dentre os meios de descolagem de bráquetes cerâmicos estudados, muitos agem pela ação do calor sendo extremamente importante avaliar a temperatura atingida na câmara pulpar para evitar iatrogenias (Jost-Brinkmann et al., 1997; Macri, 2012).

Um dos principais problemas relacionado ao uso de bráquetes cerâmicos refere-se à descolagem. Devido a pouca deformação, o procedimento é dificultado, ocasionando com certa frequência danos irreversíveis à superfície do dente (Karamouzos et al., 1997; Russell, 2005; Maltagliati et al., 2006; Jena et al., 2007).

Durante a remoção de bráquetes cerâmicos, o ideal seria que o modo de fratura ocorresse nas camadas do compósito ou na interface bráquete/compósito e não na interface dente/compósito, evitando assim a ocorrência de qualquer dano à superfície do esmalte. Bráquetes metálicos e plásticos, no momento da descolagem sofrem deformação, o que facilita o procedimento e desloca a linha de fratura para a interface bráquete/compósito. Bráquetes cerâmicos, por sofrerem pouca deformação deslocam a linha de fratura para a interface dente/compósito. Outro tipo é a fratura mista, cuja descolagem pode se localizar parte na interface dente/compósito e parte na interface bráquete/compósito (Karamouzos et al., 1997; Russell, 2005; Maltagliati et al., 2006; Jena et al., 2007).

Danos à estrutura dentária têm sido relatados em decorrência da descolagem de bráquetes cerâmicos. Autores citam fraturas no esmalte, fratura do bráquete, desconforto do paciente no momento da descolagem, maior tempo de trabalho e desgaste do profissional, risco de ferimentos tanto no paciente quanto no Ortodontista, e até mesmo aspiração de fragmentos (Karamouzos et al., 1997; Russel, 2005; Maltagliati et al., 2006; Jena et al., 2007). 
Os bráquetes cerâmicos possuem particularidades, isto se estende também no momento da descolagem. Métodos convencionais utilizados para descolagem de bráquetes metálicos são pouco eficazes com os cerâmicos. A utilização de alicates indicados pelos fabricantes da marca comercial do bráquete cerâmico pode ser alternativa, mas também apresenta resultados pouco satisfatórios (Scott Jr, 1988; Karamouzos et al., 1997; Azzeh e Feldon, 2003; Russel, 2005; Jena et al., 2007; Bishara et al., 2008). Brocas diamantadas podem ser utilizadas para o desgaste do bráquete, confeccionando-se canaleta perpendicular ao slot, fragilizando a estrutura e facilitando a remoção com alicates (Vukovich et al., 1991).

Agentes químicos contendo solventes para o compósito são outra alternativa para remoção de bráquetes cerâmicos sem que haja necessidade de força excessiva. Sua fórmula quando aplicada ao redor do bráquete tende a facilitar a remoção mecânica e diminuir os riscos de danos ao esmalte. Por existirem número limitado de estudos testando sua eficácia, essa alternativa é pouco utilizada atualmente (Winchester, 1992; Karamouzos et al., 1997; Larmour et al., 1998; Russell, 2005; Jena et al., 2007).

A instrumentação ultrassônica também foi testada com essa finalidade. Pesquisadores encontraram falhas na interface esmalte-adesivo com a utilização dessa técnica e consequente redução na força necessária para descolagem. No entanto maior tempo de trabalho, desgaste das pontas ultrassônicas, desconforto para dentes sensíveis e risco de causar algum dano pulpar caso a irrigação não seja eficiente fez com que o método fosse contraindicado (Boyer et al., 1995; Karamouzos et al., 1997; Jena et al., 2007).

Outra alternativa bastante estudada foi a descolagem eletrotérmica onde a energia térmica produzida por bateria elétrica era transferida ao bráquete, atingia o compósito que sofria deformação, permitindo que o bráquete fosse deslocado facilmente da superfície dentária. A possibilidade de lesões à mucosa oral e danos ao tecido pulpar devido ao aumento de temperatura foram os motivos que fizeram a técnica ser abandonada (Bishara et al., 1988; Dovgan et al., 1995; Takla et al., 1995; Vargas, 1996; Karamouzos et al., 1997; Kearns et al., 1997; Cummings et al., 1999; Russell, 2005; Jena et al., 2007.)

Um dos caminhos para a descolagem de bráquetes cerâmicos está no amolecimento do compósito por meio da transmissão de calor. Tomando por referência este princípio a utilização de lasers como o de Diodo (Feldon et al., 2010), Tm: YAP (Dostalova et al., 2011), Nd:YAG (Hayakawa, 2005; Han et al., 2008), Er:YAG (Oztoprak et al., 2010; Nalbantgil et al., 2010; Tozlu et al., 2011), Itérbio (Sarp e Gülsoy, 2010), Argônio (Weinberger et al., 1997) e $\mathrm{CO}_{2}$ (Strobl et al., 1992; Rickabaugh et al., 1996; Obata et al., 1999; Iijima et al., 2010; Tehranchi et al., 2010; Ahrari et al., 2011; Macri, 2012; Pessoti et al., 2012) tem ganhado espaço entre as linhas de pesquisas. 
O laser de $\mathrm{CO}_{2}$ foi desenvolvido em 1964 por Patel et al., se destaca na realização de procedimentos cirúrgicos e tem sido bastante estudado na Odontologia para inibição da desmineralização (Souza-Gabriel et al., 2010; Correa-Afonso et al., 2012; Stangler, 2012). No entanto, sua utilização para descolagem de bráquetes cerâmicos ainda é recente. Devido aos vários modos de utilização (contínuo, pulsado e interrompido) há grande variação de potência e de comprimentos de onda. Sua principal ação sobre os compósitos é o amolecimento, embora a alta temperatura emitida possa também afetar o esmalte causando carbonização, trincas, fissuras e ablação (Scott-Jr, 1988; Bishara et al., 1994; Ahrari et al., 2011). A correta escolha da potência e tempo utilizados evita a ocorrência de danos à superfície do esmalte e à polpa. Segundo Macri (2012), a potência de $10 \mathrm{~W}$ e o tempo de 3 segundos com intervalo de pulso de 0,01 segundo foi capaz de fragilizar o compósito facilitando a descolagem e atingindo temperatura de $4,7^{\circ} \mathrm{C}$ na câmara pulpar, o que é biologicamente aceito (Zach e Cohen, 1965). A eficiência do laser de $\mathrm{CO}_{2}$ na descolagem de bráquetes cerâmicos está cada vez mais clara entre os pesquisadores da área (Strobl et al., 1992; Obata et al., 1999; Tehranchi et al., 2010; Ahrari et al., 2011; Macri, 2012). Pessoti et al. (2012), utilizando o laser de $\mathrm{CO}_{2}$ nos parâmetros $10 \mathrm{~W}, 3$ segundos, intervalo de pulso de 0,01s no modo Ultra Pulse, encontrou uma redução significativa na resistência ao cisalhamento após irradiação dos grupos experimentais, os autores encontraram ainda uma grande quantidade de remanescente adesivo sobre as superfícies, demostrando diminuição dos riscos de ocorrência de danos ao esmalte após descolagem com laser de $\mathrm{CO}_{2}$.

A variedade de metodologias utilizadas nas pesquisa de descolagem de bráquetes cerâmicos com laser de $\mathrm{CO}_{2}$ e a falta de padronização dos parâmetros de irradiação deixam claro a necessidade de mais estudos nesta área visando a avaliação do equipamento, a criação e consolidação de protocolos, além da confirmação da sua eficácia, eficiência e efetividade. 
Proposição 


\section{Proposição}

O presente trabalho propõe-se avaliar e comparar:

a) a resistência ao cisalhamento de bráquetes cerâmicos com retenção química e mecânica, colados com diferentes compósitos e irradiados com laser de $\mathrm{CO}_{2} ;$

b) o Índice de Remanescente Adesivo (IRA) após a descolagem dos bráquetes cerâmicos;

c) o modo de fratura e a ocorrência de danos ao esmalte dental durante o processo de descolagem. 
Material e Métodos 


\section{Material e Métodos}

Previamente a sua realização, esta pesquisa foi submetida e aprovada pelo Comitê de Ética em Pesquisas da Faculdade de Odontologia de Ribeirão Preto da Universidade de São Paulo com o protocolo CAAE 0054.0.138.000-11 (Anexo I).

A metodologia foi dividida em 3 etapas, sendo que a primeira teve o objetivo de avaliar a resistência ao cisalhamento de bráquetes cerâmicos com base de retenção química e mecânica, colados com três diferentes compósitos e irradiados com laser de $\mathrm{CO}_{2}$. A segunda avaliou o Índice de Remanescente Adesivo (IRA) após a descolagem dos bráquetes cerâmicos. Na terceira etapa foi avaliada a ocorrência de possíveis danos ao esmalte dental durante o processo de descolagem por meio de MEV.

Para a confecção dos corpos de prova, foram utilizados 120 pré-molares humanos superiores e inferiores doados pelo Banco de Dentes da Faculdade de Odontologia de Ribeirão Preto - USP com coroas intactas, sem trincas ou descalcificações, que não foram submetidos a tratamento ortodôntico ou químico. Estes dentes (Figura 1) foram limpos com curetas periodontais (Duflex, Juiz de Fora, MG, Brasil), removendo restos ósseos e de tecido mole aderidos à raiz, em seguida foram imersos em solução aquosa de timol 0,1\% por uma semana para desinfecção. Posteriormente foram lavados em água corrente e estocados em água destilada em refrigerador à temperatura de aproximadamente $4^{\circ} \mathrm{C}$ até o início da confecção dos corpos de prova.

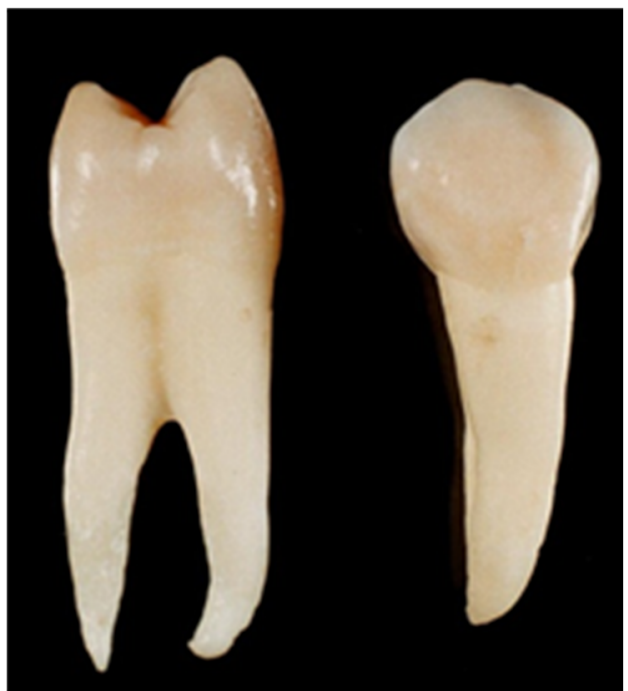

Figura 1- Pré-molar humano (vista lateral e vestibular). 
A coroa destes dentes foi coberta com resina acrílica autopolimerizável de cor rosa (Jet Clássico, São Paulo, SP, Brasil) e a face vestibular de cada dente foi pressionada em placa de vidro antes da reação de presa (Figura 2).

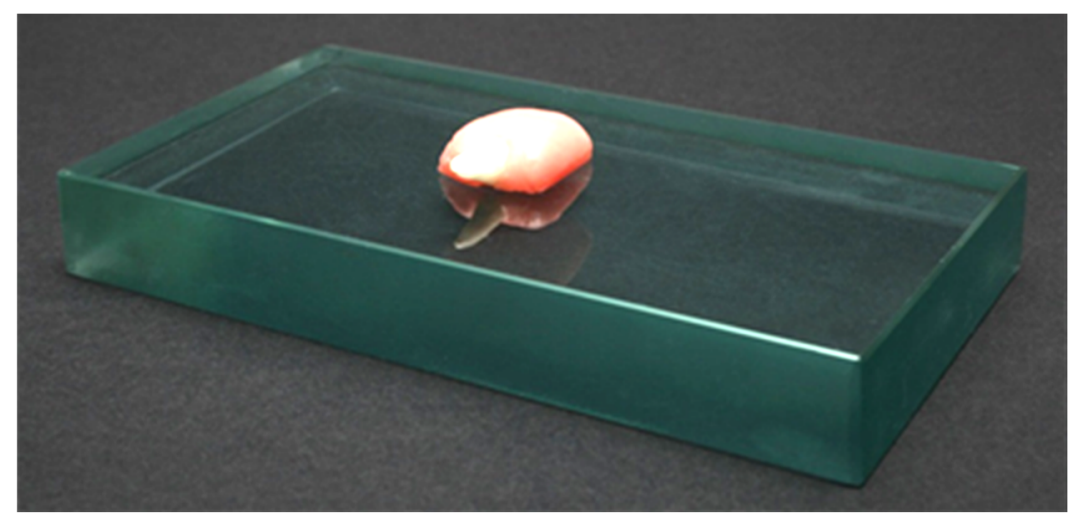

Figura 2 - Corpo de prova com a face vestibular pressionada sobre placa de vidro.

A seguir, esta mesma face foi preparada com lixas d'água de numeração 400, 600 e 1200 em politriz (Politriz DP-902, Struers A/S, Copenhagen, Denmark) até atingir área de esmalte de aproximadamente $5 \mathrm{~mm}$, área esta suficiente para colagem do bráquete (Figura 3 A e B).
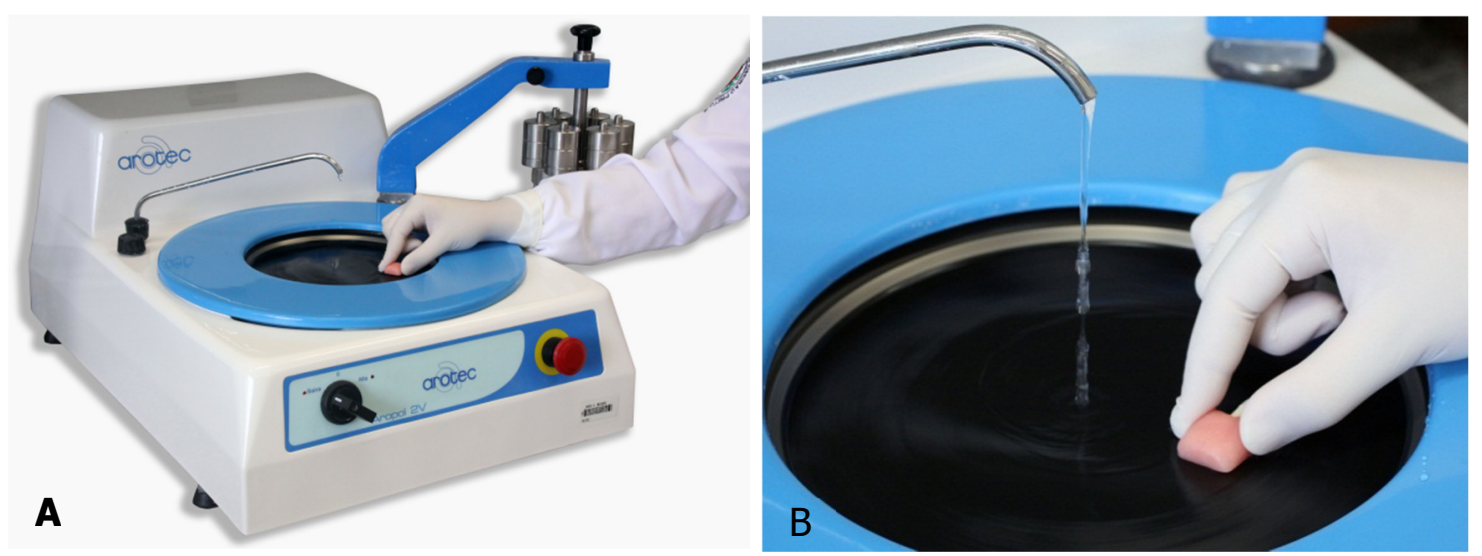

Figura 3 - A - Politriz utilizada para lixar os corpos de prova; B - Corpo de prova na politriz.

Na sequência, as raízes dos dentes foram incluídas centralizadas em tubos de PVC (Tigre, Rio Claro, SP, Brasil) e o tubo preenchido com resina acrílica autopolimerizável (Jet Clássico, São Paulo, SP, Brasil) (Figura 4, página 36). 


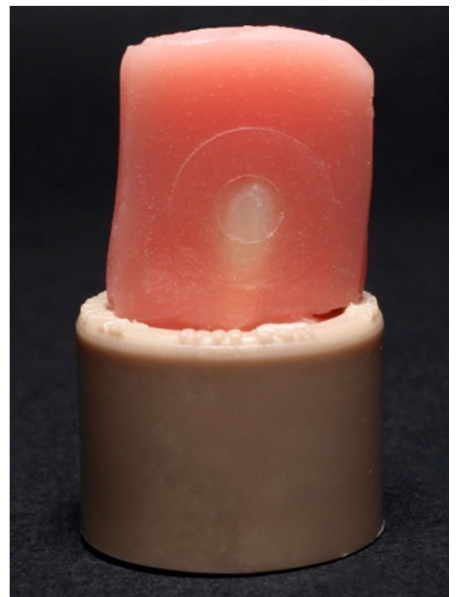

Figura 4 - Corpo de prova com a raiz incluída em tubo de PVC contendo resina acrílica.

Para correto ensaio de resistência ao cisalhamento, durante a inclusão das raízes a face vestibular de cada dente foi posicionada perpendicularmente à base do tubo com auxílio de esquadro de vidro em formato de "L" $\left(90^{\circ}\right)$, especialmente construído para este fim (Figura 5). Os dentes que não estavam corretamente posicionados foram excluídos e substituídos. Os excessos de resina foram removidos com espátula lecron e os dentes permaneceram armazenados em recipientes plásticos contendo água destilada e estocados em geladeira.

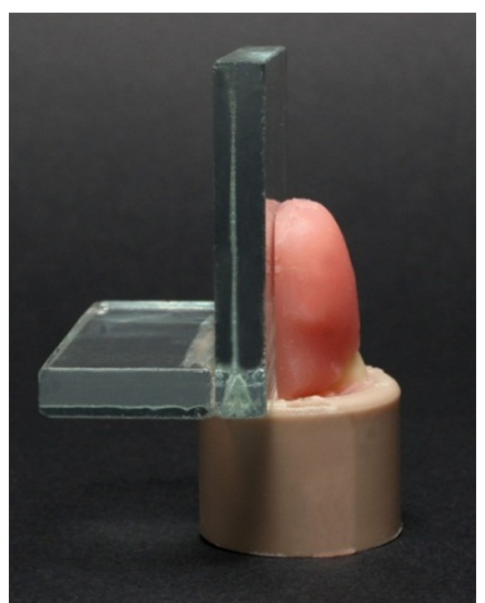

Figura 5 - Esquadro de vidro apoiado no troquel e no dente para verificar posicionamento.

Foram confeccionados 120 corpos de prova divididos aleatoriamente em oito grupos $(n=15)$ que se diferenciaram pelo tipo de bráquete (retenção química ou mecânica na base), compósito utilizado (Transbond XT, Concise ou Z 250) e irradiação ou não de laser de $\mathrm{CO}_{2}$ sobre o bráquete. Os grupos que receberam irradiação de laser $\mathrm{CO}_{2}$ foram os grupos experimentais e os que não receberam irradiação foram os 
grupos controle. A Tabela 1 traz informações relativas aos materiais utilizados neste trabalho. As Figuras 6 A, B, C e D ilustram os bráquetes utilizados e a Tabela 2 (página 38) ilustra os grupos de pesquisa.

Tabela 1- Informações relativas aos materiais utilizados no estudo.

\begin{tabular}{ccccc}
\hline Material & Nome comercial & Fabricante & Origem & $\begin{array}{c}\text { Lote / } \\
\text { Referência }\end{array}$ \\
\hline Agente de união & Single Bond 2 & 3M ESPE & St. Paul, MN, USA & 8 RY / 51202 \\
Agente de união & XT Primer & 3M Unitek & Monrovia, CA, USA & N198258 \\
Bráquete & Mystique & GAC & New York, NY, USA & $110-312-00$ \\
Bráquete & Fascination & Dentaurum & Ispringen, BW, Alemanha & $700-066-00$ \\
Compósito & Transbond XT & 3M Unitek & Monrovia, CA, USA & N182301 \\
Compósito & Concise Ortodôntico & 3M do Brasil & Sumaré, SP, Brasil & 1124100560 \\
Compósito & Z 250 & 3M ESPE & St. Paul, MN, USA & $7 \mathrm{LX}$ \\
\hline
\end{tabular}
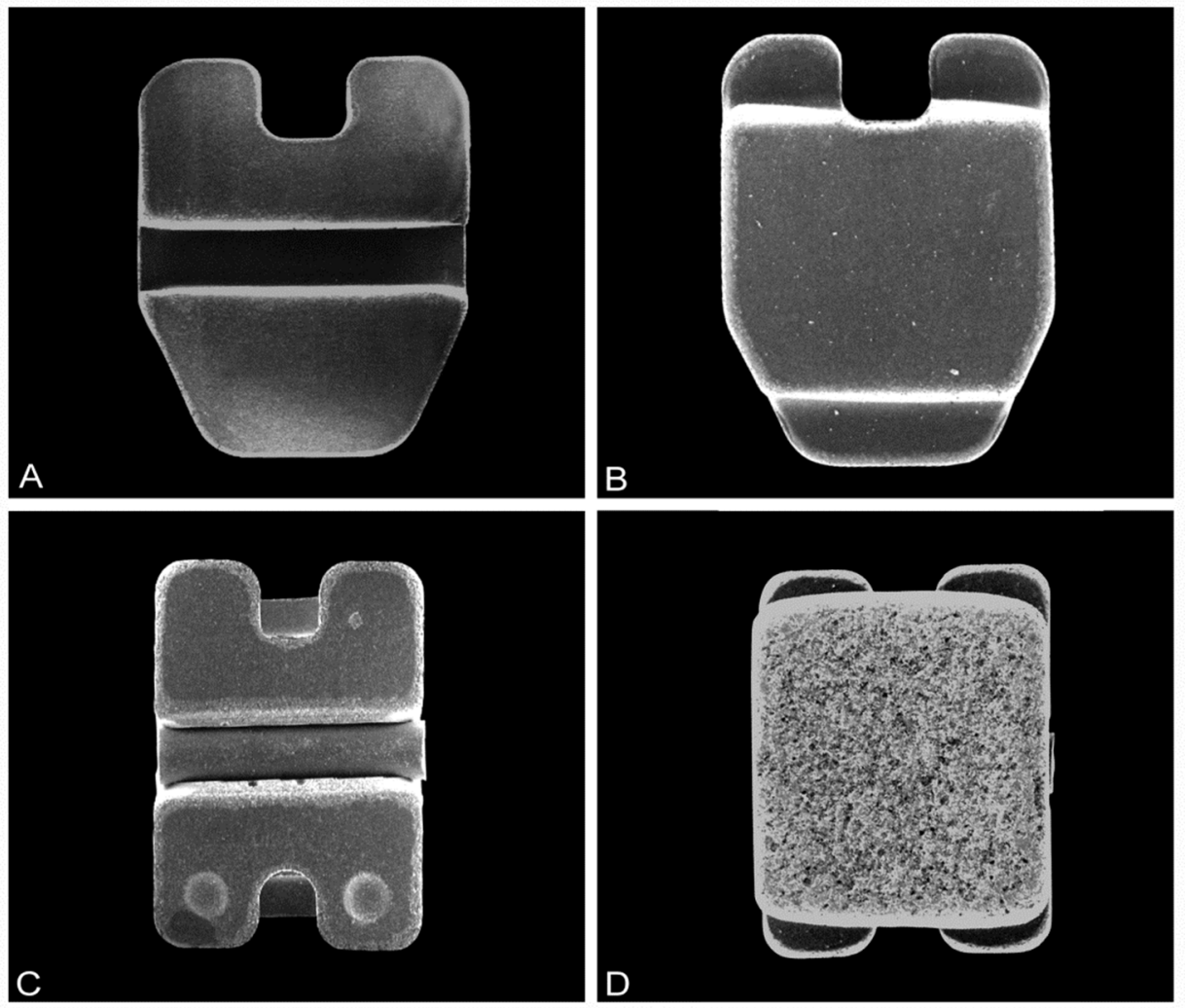

Figura 6 - A - Bráquete Fascination (vista frontal); B - Base de retenção química; C - Bráquete Mystique (vista frontal); D - Base de retenção mecânica. 
Tabela 2 - Grupos controles e experimentais

\begin{tabular}{ccccc}
\hline Grupo & Compósito & $\begin{array}{c}\text { Bráquete } \\
\text { cerâmico }\end{array}$ & $\begin{array}{c}\text { Retenção da } \\
\text { Base }\end{array}$ & $\begin{array}{c}\text { Irradiação com } \\
\text { Laser de } \text { CO }_{\mathbf{2}}\end{array}$ \\
\hline 1 (Controle) & Transbond XT & Mystique & Mecânica & Não \\
2 (Controle) & Transbond XT & Fascination & Química & Não \\
3 & Transbond XT & Mystique & Mecânica & Sim \\
4 & Concise Ortodôntico & Mystique & Mecânica & Sim \\
5 & Z 250 & Mystique & Mecânica & Sim \\
6 & Transbond XT & Fascination & Química & Sim \\
7 & Concise Ortodôntico & Fascination & Química & Sim \\
8 & Z 250 & Fascination & Química & Sim \\
\hline
\end{tabular}

Para melhor visualização os grupos foram abreviados da seguinte forma:

- Grupo 1: TMC - Transbond XT + Mystique + Controle

- Grupo 2: TFC - Transbond XT + Fascination + Controle

- Grupo 3: TML - Transbond XT + Mystique + Laser

- Grupo 4: CML - Concise Ortodôntico + Mystique + Laser

- Grupo 5: ZML - Z 250 + Mystique + Laser

- Grupo 6: TFL - Transbond XT + Fascination + Laser

- Grupo 7: CFL - Concise Ortodôntico + Fascination + Laser

- Grupo 8: ZFL - Z 250 + Fascination + Laser

Previamente a colagem dos bráquetes, na face vestibular dos dentes foi delimitada área circular de 4,5mm de diâmetro com fita adesiva (3L Reinforcement Rings, Odense, Fyn, Danmark). Em seguida, esta área recebeu profilaxia com pasta de pedra pomes sem flúor e água com taça de borracha em motor de baixa rotação por 10 segundos, acompanhada de lavagem por 10 segundos e secagem com seringa tríplice isenta de óleo e umidade pelo mesmo período de tempo (Figura 7).

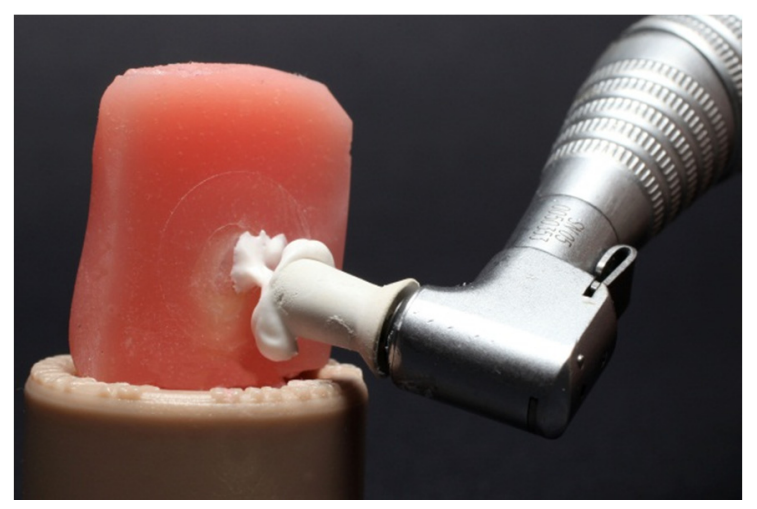

Figura 7 - Profilaxia da superfície. 
Após a profilaxia foi realizado o condicionamento do esmalte com ácido fosfórico a $37 \%$ por 15 segundos, seguido de lavagem e secagem, ambas pelo mesmo período de tempo (Figura 8).

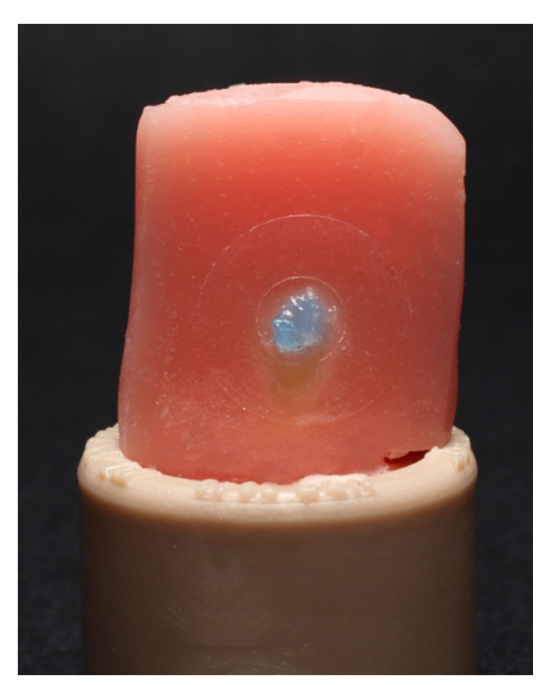

Figura 8 - Condicionamento ácido do esmalte.

Nos grupos 1, 2, 3 e 6, após a secagem do condicionamento, foi aplicada camada do agente de união XT primer (3M Unitek, Monrovia, CA, USA) e leve jato de ar para espalhar o material. Nos grupos 4 e 7, após o condicionamento ácido foi aplicado sobre o esmalte a resina fluida A e B homogeneizada que acompanha 0 compósito Concise Ortodôntico e posteriormente leve jato de ar direcionado a superfície. Nos grupos 5 e 8 foi utilizado o agente de união Single Bond e polimerizado por 20 segundos (3M ESPE, Sumaré, SP, Brasil).

Para a colagem foi utilizada pinça de apreensão (Ortoply, Philadelphia, MN, USA), Os bráquetes foram posicionados e pressionados nas áreas vestibulares previamente preparadas. Os excessos de compósitos ao redor dos bráquetes foram removidos com sonda exploradora. Nos grupos 1, 2, 3, 5, 6 e 8 foi realizada fotoativação de cada colagem por 40 segundos, sendo 10 segundos em cada face (mesial, distal, incisal e gengival) com aparelho de luz halógena XL 1500 (3M ESPE, St. Paul, MN, USA) à distância de $1 \mathrm{~mm}$ do bráquete. A cada quatro fotoativações, a intensidade de luz do aparelho foi aferida com radiômetro (Demetron, Danbury, CT, USA) e atingiu $400 \mathrm{~mW} / \mathrm{cm}^{2}$. 
Os corpos de prova após a colagem (Figura 9 A e B) foram conservados intactos por 30 minutos e depois armazenados em água destilada por 24 horas em estufa a temperatura de $37^{\circ} \mathrm{C}$ na tentativa de simular as condições bucais.
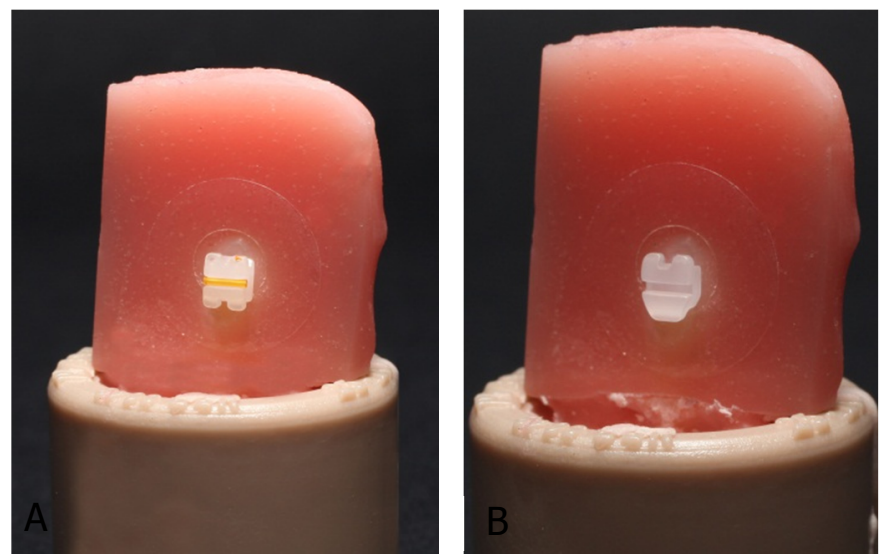

Figura 9 - A - Corpo de prova após colagem do bráquete de retenção mecânica Mystique; B - Corpo de prova após colagem do bráquete de retenção química Fascination.

Após esse período, os grupos controles foram submetidos ao ensaio de resistência ao cisalhamento em máquina universal de ensaios mecânicos (Emic DL 500, São José dos Pinhais, PR, Brasil) a velocidade de $0,5 \mathrm{~mm}$ por minuto com ponta ativa em cinzel apoiada na interface compósito/esmalte (Figura 10).

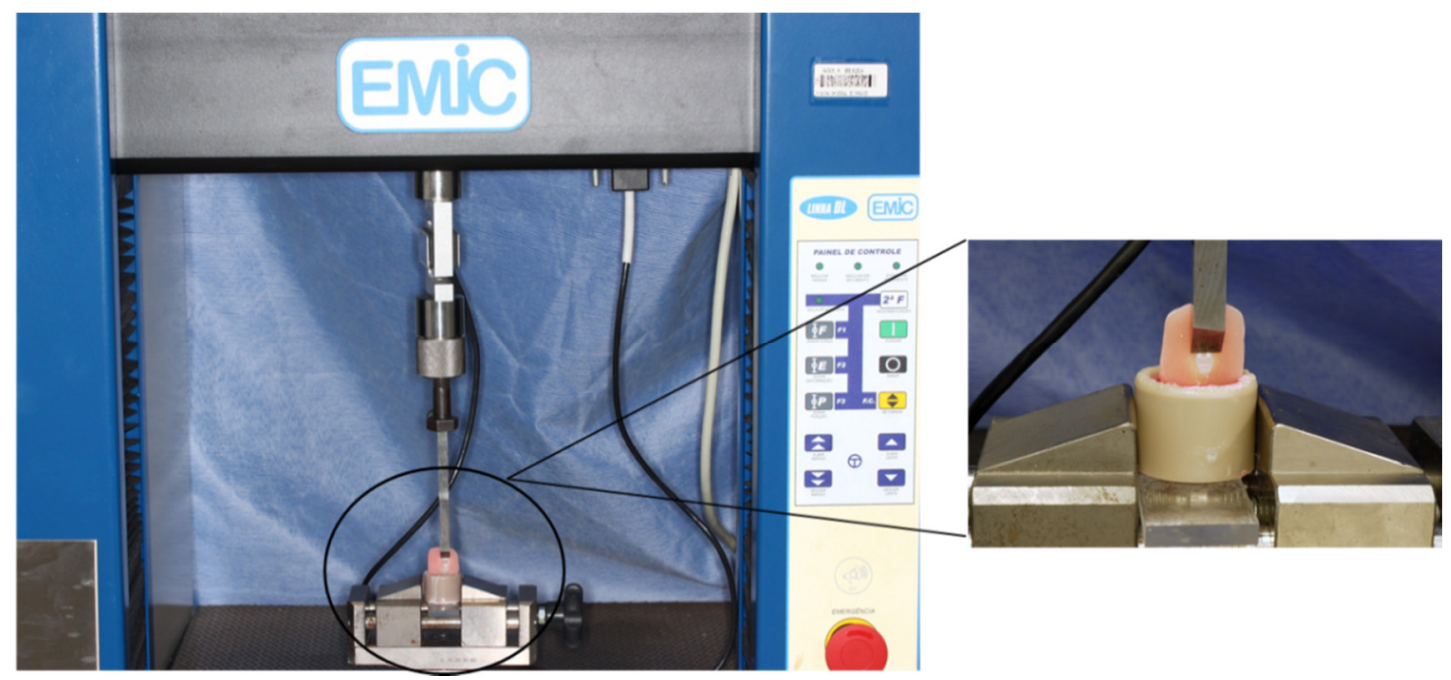

Figura 10- Ensaio de resistência ao cisalhamento. 
Os grupos experimentais também foram submetidos ao ensaio de resistência ao cisalhamento, porém, imediatamente antes do teste foram irradiados com laser de $\mathrm{CO}_{2}$ com comprimento de onda de 10,6 $\mu \mathrm{m}$ (Shangai Jue Hera Technology Development Shangai, PR, China) (Figura 11) no centro do bráquete cerâmico utilizando potência de $10 \mathrm{~W}$ por 3 segundos e pulso de 0,01 segundo, à uma distância de $4 \mathrm{~mm}$ padronizada com o auxílio de um fio ortodôntico acoplado à ponta ativa do aparelho (Macri, 2012) (Figura 12).

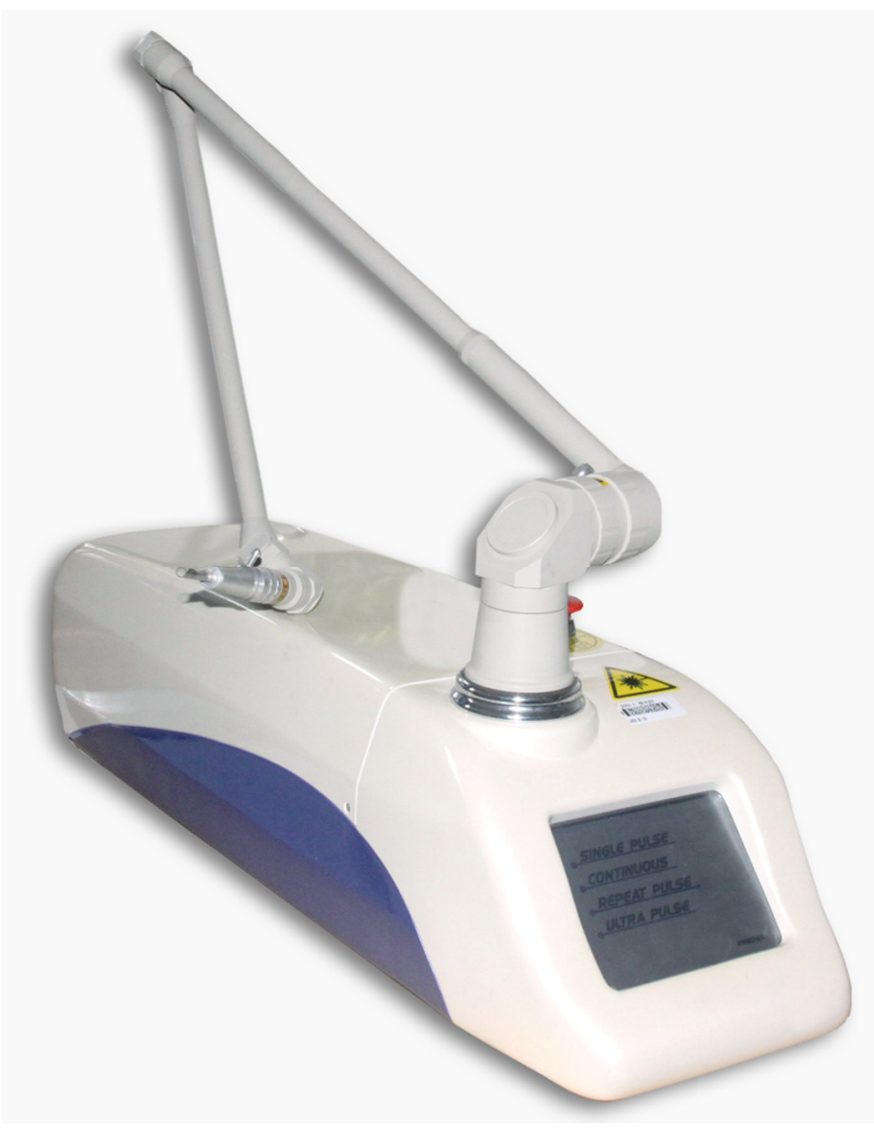

Figura 11 - Aparelho de laser de $\mathrm{CO}_{2}$.

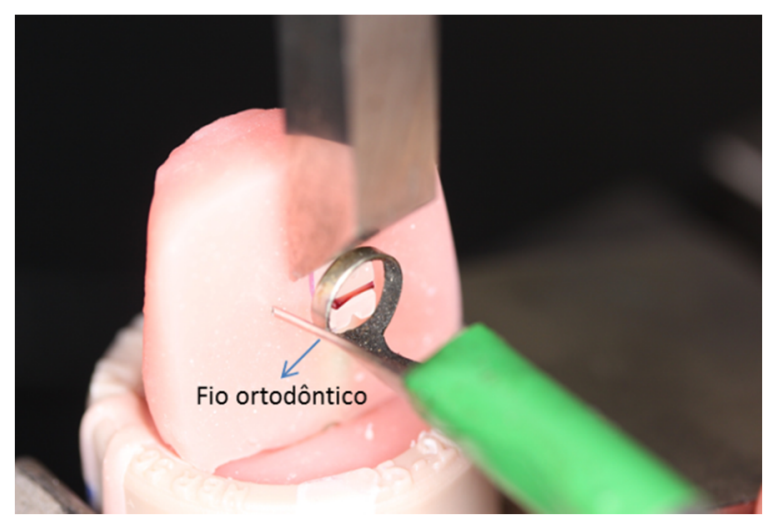

Figura 12 - Irradiação do laser e ensaio de resistência ao cisalhamento. 
Os valores do ensaio de resistência ao cisalhamento foram obtidos em MPa fornecidos pelo próprio equipamento e submetidos a análise estatística, empregando o teste ANOVA e Tukey. O nível de significância adotado foi de 5\%.

\section{AVALIAÇÃO DO ÍNDICE DE REMANESCENTE ADESIVO (IRA)}

Após a descolagem do bráquete, o esmalte dentário de todos os corpos de prova foram avaliados por meio de lupa estereoscópica (Carl Zeiss, Goettingen, NI, Alemanha) e classificados de acordo com os escores propostos por Artun \& Bergland (1984): 0- nenhuma quantidade de compósito aderido ao esmalte; 1- menos da metade do compósito aderido ao esmalte; 2- mais da metade do compósito aderido ao esmalte; 3- todo o compósito aderido ao esmalte (Figura 13 A, B, C e D). Foi utilizado o teste de Mann-Whitney para comparação entre os grupos.
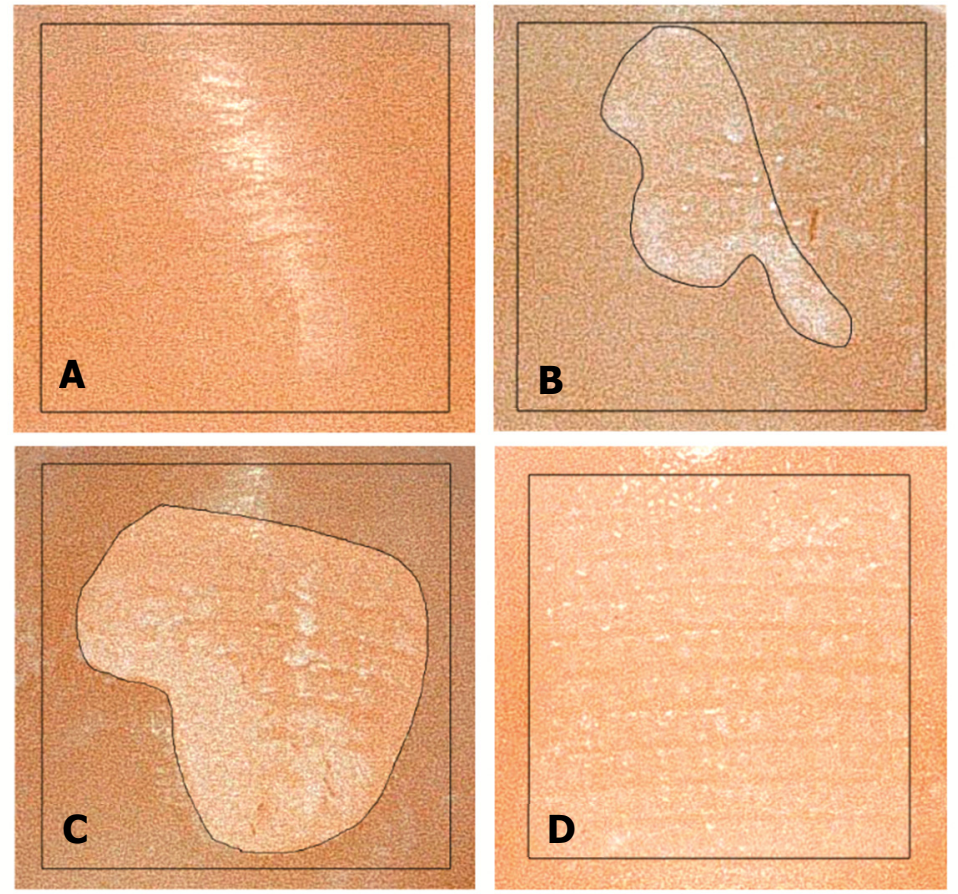

Figura 13 - Imagem ilustrativa da superfície vestibular dos corpos de prova após a descolagem. A- IRA 0; B- IRA 1; C- IRA 2 e D - IRA 3. 


\section{MICROSCOPIA ELETRÔNICA DE VARREDURA (MEV)}

As superfícies vestibulares de todos os corpos de prova onde os bráquetes foram colados foram avaliadas e submetidas MEV para investigar o modo de fratura. Inicialmente as peças foram desidratadas e seccionadas, posteriormente foram transportadas ao Laboratório de Microscopia da Universidade Júlio de Mesquita Filho - UNESP, câmpus Jaboticabal, para serem metalizadas em ouro sob vácuo, em aparelho Desk II (Denton Vacuum, LLC, Moorestown, USA) durante 120 segundos. O preparo das amostras seguiu os seguintes passos:

As amostras foram fixadas em glutaraldeído à $3 \%$ em tampão fosfato de potássio por 48 horas, lavadas em tampão 3 a 4 vezes e pós fixadas em tetróxido de ósmio por 6 horas. Em seguida as amostras foram novamente lavadas em tampão de 3 a 4 vezes. Para a desidratação das amostras foi utilizado série alcóolica crescente, 30\%, 50\%, 70\%, 80\%, $90 \%$ e $100 \%$ (todos com intervalo de 20 minutos). As amostras foram secadas em secador de ponto crítico para posterior metalização em ouro por 120 segundos. Em seguida a análise foi efetuada em microscópio eletrônico de varredura (EVO 50® - Carl Zeiss SMT, Gottingen, Germany) a $20.00 \mathrm{KV}$.

Após obtidas as imagens, estas foram classificadas quanto ao modo de fratura descrito abaixo (Ramos, 2003):

- Fratura Adesiva (Ad): Quando a fratura foi observada entre o compósito e o esmalte.

- Fratura Coesiva Resina (CR): Quando a fratura ocorreu entre o bráquete e o compósito de maneira que o compósito permanecesse aderido ao esmalte.

- Fratura Coesiva Esmalte (CE): Quando a fratura se deu sobre a superfície dental removendo parte do esmalte.

- Fratura Mista Coesiva Resina/Adesiva (CR/Ad): Quando em um mesmo corpo de prova houve fratura entre o bráquete e o compósito com parte de compósito permanecendo sobre a superfície dental e em outra parte a fratura se deu entre o compósito e o esmalte.

- Fratura Mista Coesiva Esmalte/Adesiva (CE/Ad): Quando em um mesmo corpo de prova houve remoção parcial da estrutura dental e em outra parte a fratura se deu entre o compósito e o esmalte.

- Fratura Mista Coesiva Resina/Coesiva Esmalte (CR/CE): Quando em um mesmo corpo de prova parte do compósito permaneceu sobre a superfície dental e em outra parte remoção parcial da estrutura dental. 
O fluxograma a seguir ilustra os principais procedimentos metodológicos (Figura 14).

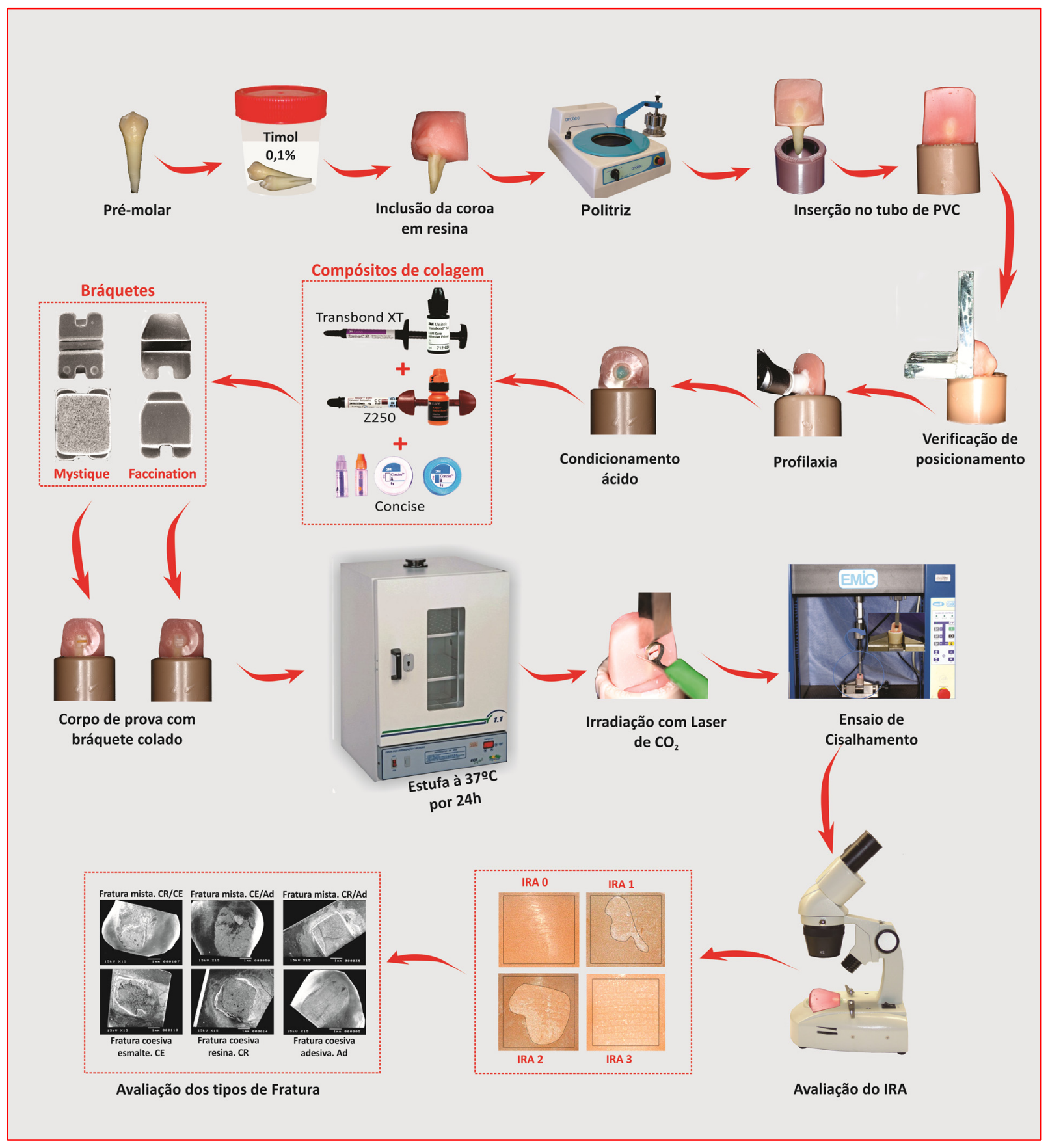

Figura 14 - Fluxograma da parte metodológica. 
Resultados 
Resultados

Para efeito de análise estatística os seguintes fatores foram considerados: bráquete, compósito e laser. Os valores médios de resistência da união ao cisalhamento foram submetidos à Análise de Variância (ANOVA) e posteriormente ao teste de Tukey com 5\% de significância (Tabela 3).

Tabela 3 - Valores médios de resistência ao cisalhamento (MPa), desvio padrão (DP) e comparação estatística.

\begin{tabular}{ccc}
\hline Compósito & Mystique (DP) & Fascination (DP) \\
\hline Controle (Transbond XT) & $7,63(1,3) \mathrm{bA}$ & $4,45(0,68) \mathrm{bB}$ \\
Transbond XT & $3,45(0,68) \mathrm{aA}$ & $0,92(0,18) \mathrm{aB}$ \\
Concise Ortodôntico & $3,26(1,18) \mathrm{aA}$ & $1,02(0,26) \mathrm{aA}$ \\
Z 250 & $3,52(1,04) \mathrm{aA}$ & $0,28(0,70) \mathrm{aB}$
\end{tabular}

Letras iguais, minúsculas entre linhas e maiúsculas entre colunas, ausência de diferença estatística significante.

Os valores obtidos no ensaio de resistência ao cisalhamento evidenciaram a ação do laser sobre os grupos experimentais onde as médias obtidas foram significativamente menores quando comparadas ao controle.

Na colagem com bráquetes Mystique não houve diferenças estatísticas significantes entre os compósitos quando os grupos experimentais foram comparados, o mesmo aconteceu com os grupos experimentais do bráquetes Fascination ( $p>0,05)$.

$\mathrm{Na}$ comparação entre os tipos de bráquetes, as colagens realizadas com os bráquetes Mystique e irradiadas com laser de $\mathrm{CO}_{2}$ obtiveram valores adesivos estatisticamente superiores a dos bráquetes Fascination $(p<0,05)$, com exceção do compósito Concise Ortodôntico, onde não foram encontradas diferenças estatísticas significantes entre os bráquetes ( $p>0,05)$.

Com relação ao tipo de retenção dos bráquetes utilizados nessa pesquisa, a base com retenção mecânica apresentou valores maiores de resistência ao cisalhamento que a química, tanto para o grupo controle como para os grupos experimentais.

Quando os compósitos foram analisados, o Z 250 associado ao bráquete Fascination (retenção química) foi o que apresentou menor força de adesão após irradiação com laser de $\mathrm{CO}_{2}$. Já para os grupos que utilizaram o bráquete Mystique (retenção mecânica), o menor valor médio de resistência ao cisalhamento foi encontrado no grupo que utilizou o compósito Concise Ortodôntico. 
As diferenças estatísticas (valores de p) encontradas entre os grupos estão descritas na Tabela 4.

Tabela 4 - Resultados do teste de Tukey para comparação entre os grupos

\begin{tabular}{|c|c|c|c|c|c|}
\hline Comparação & Diferença & Valores dep & Comparação & Diferença & Valores dep \\
\hline TMC $\times$ TFC & $-4,188$ & 0,206 & TML $\times$ ZML & $-0,074$ & 1,000 \\
\hline TMC $\times$ TML & 4,188 & 0,206 & TML $\times$ TFL & 2,520 & 0,760 \\
\hline TMC $\times$ CML & 4,373 & 0,171 & TML $\times$ CFL & 2,424 & 0,799 \\
\hline TMC x ZML & 4,114 & 0,221 & $\mathrm{TML} \times \mathrm{ZFL}$ & 3,187 & 0,472 \\
\hline TMC $\times$ TFL & 6,709 & 0,000 & CML $\times$ ZML & $-0,258$ & 1,000 \\
\hline TMC $\times$ CFL & 6,613 & 0,000 & CML $\times$ TFL & 2,336 & 0,832 \\
\hline TMC $\times$ ZFL & 7,375 & 0,000 & CML $\times$ CFL & 2,240 & 0,864 \\
\hline TFC $\times$ TML & 1,000 & 0,999 & CML $\times$ ZFL & 3,002 & 0,560 \\
\hline TFC $\times C M L$ & 1,184 & 0,998 & ZML $\times$ TFL & 2,594 & 0,728 \\
\hline TFC $\times$ ZML & 0,926 & 1,000 & ZML $\times$ CFL & 2,498 & 0,769 \\
\hline TFC $\times$ TFL & 3,520 & 0,000 & $\mathrm{ZML} \times \mathrm{ZFL}$ & 3,261 & 0,438 \\
\hline TFC $\times$ CFL & 3,424 & 0,000 & TFL $\times$ CFL & $-0,960$ & 1,000 \\
\hline TFC $\times$ ZFL & 4,167 & 0,000 & TFL $x$ ZFL & 0,646 & 0,809 \\
\hline $\mathrm{TML} \times \mathrm{CML}$ & 0,184 & 1,000 & CFL $\times$ ZFL & 0,742 & 0,718 \\
\hline
\end{tabular}

$\overline{p<0,05-\text { diferença estatística significante }}$

A Tabela 5 abaixo mostra a média do Índice de Remanescente Adesivo (IRA) encontrada nos grupos e a comparação estatística entre eles por meio do teste de MannWhitney.

Tabela 5 - Resultados médios do IRA

\begin{tabular}{ccc}
\hline & Mystique & Fascination \\
\hline Controle & $0,6 \mathrm{a}$ & $1,53 \mathrm{bc}$ \\
Transbond XT & $1,2 \mathrm{abc}$ & $1,6 \mathrm{c}$ \\
Concise & $1,2 \mathrm{abc}$ & $0,8 \mathrm{ab}$ \\
Z 250 & $1,86 \mathrm{c}$ & $2,66 \mathrm{~d}$
\end{tabular}

Letras iguais indicam semelhança estatística $(p<0,05)$.

A tabela 5 mostra que a menor média encontrada entre os grupos foi para o grupo controle TMC seguido pelo grupo experimental CFL evidenciando maior número de escores 0 para esses grupos. Os grupos que apresentaram melhores resultados foram os grupos experimentais ZFL e ZML, ambos utilizaram o compósito Z 250, com predominância de escores 3 e 2 ou seja, apresentaram maior quantidade de remanescente adesivo após a descolagem, diminuindo os riscos de danos à superfície do esmalte. 
A Figura 15 ilustra os valores dos escores do IRA encontrados nos grupos.

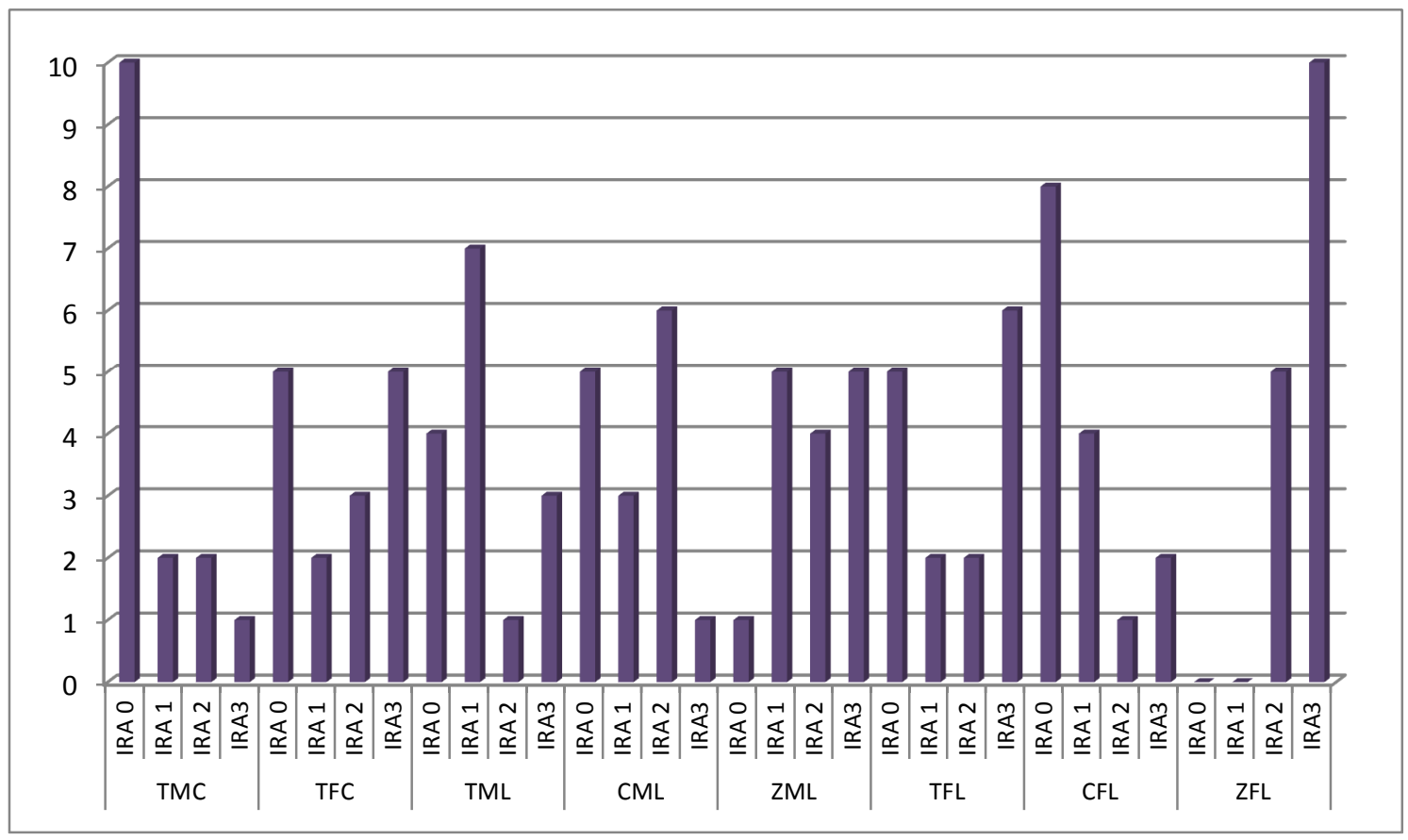

Figura 15 - Escores do Índice de Remanescente Adesivo (IRA) encontrado nos grupos.

Os corpos de prova do grupo ZFL somente apresentaram escores 2 e 3 que configuram maior quantidade de remanescente adesivo, sendo o escore 3 o encontrado em maior quantidade. Em contrapartida o grupo TMC foi o que apresentou maior quantidade de escore 0 seguido pelo grupo CFL, portanto, obtiveram menor média ou seja, após a descolagem esses grupos apresentaram menor quantidade de remanescente adesivo sobre a superfície dentária estando mais sujeitos a danos a superfície dental.

Na avaliação por meio de MEV, 109 dos 120 espécimes foram submetidos à análise, sendo que 11 foram perdidos durante o corte e preparo para a leitura. As superfícies foram avaliadas e classificadas quanto ao tipo de fratura podendo ser Fratura Adesiva (Ad), Fratura Coesiva Resina (CR), Fratura Coesiva Esmalte (CE), Fratura Mista Coesiva Resina/Adesiva (Mista CR/Ad), Mista Coesiva Esmalte/Adesiva (Mista CE/Ad), Mista Coesiva Resina/Coesiva Esmalte (Mista CR/CE). A Tabela 6 (página 49) quantifica os tipos de fratura encontrados em cada grupo. 
Tabela 6 - Tipos de fraturas encontradas nos grupos.

\begin{tabular}{ccccccc}
\hline Grupos & Ad & CR & CE & $\begin{array}{c}\text { Mista } \\
\text { CR/Ad }\end{array}$ & $\begin{array}{c}\text { Mista } \\
\text { CE/Ad }\end{array}$ & $\begin{array}{c}\text { Mista } \\
\text { CR/CE }\end{array}$ \\
\hline TFC & 6 & 4 & & 4 & & \\
TMC & 8 & 2 & 2 & 2 & & \\
TML & 6 & 5 & & 4 & 1 & \\
CML & 7 & 1 & & 2 & 1 & 2 \\
ZML & 2 & 4 & 3 & 2 & 3 & 1 \\
TFL & 3 & 5 & 1 & 2 & 1 & \\
CFL & 9 & & & 2 & 1 & \\
ZFL & 1 & 8 & & 3 & 1 & \\
\hline
\end{tabular}

O modo de fratura encontrado com maior frequência foi a Fratura Adesiva, ocorrendo em 42 das 109 microscopias avaliadas. O grupo CFL foi o que apresentou maior índice de Fratura Adesiva, justificando também ser esse o grupo que apresentou menor valor médio para o remanescente adesivo ou seja, maior quantidade de escore 0 . 0 segundo tipo de fratura mais encontrado foi a Fratura Coesiva Resina com 29 espécimes, sendo que o grupo ZFL obteve a maior quantidade e também o que apresentou menos danos à superfície dental, estando de acordo com os resultados encontrado para a avaliação do IRA onde esse grupo obteve os maiores índices de escores 2 e 3. A Fratura Mista CR/Ad foi encontrada em 21 corpos de prova, Fratura Mista CE/Ad em 8, Fratura Coesiva Esmalte em 6 e Fratura Mista $\mathrm{CR} / \mathrm{CE}$ em 3 corpos de prova. O grupo que apresentou maiores danos à superfície dental foi o grupo ZML com 3 Fraturas Coesivas de Esmalte e uma mista CR/CE.

A Figura 16 (página 50) ilustra os tipos de fratura encontradas nas amostras. 

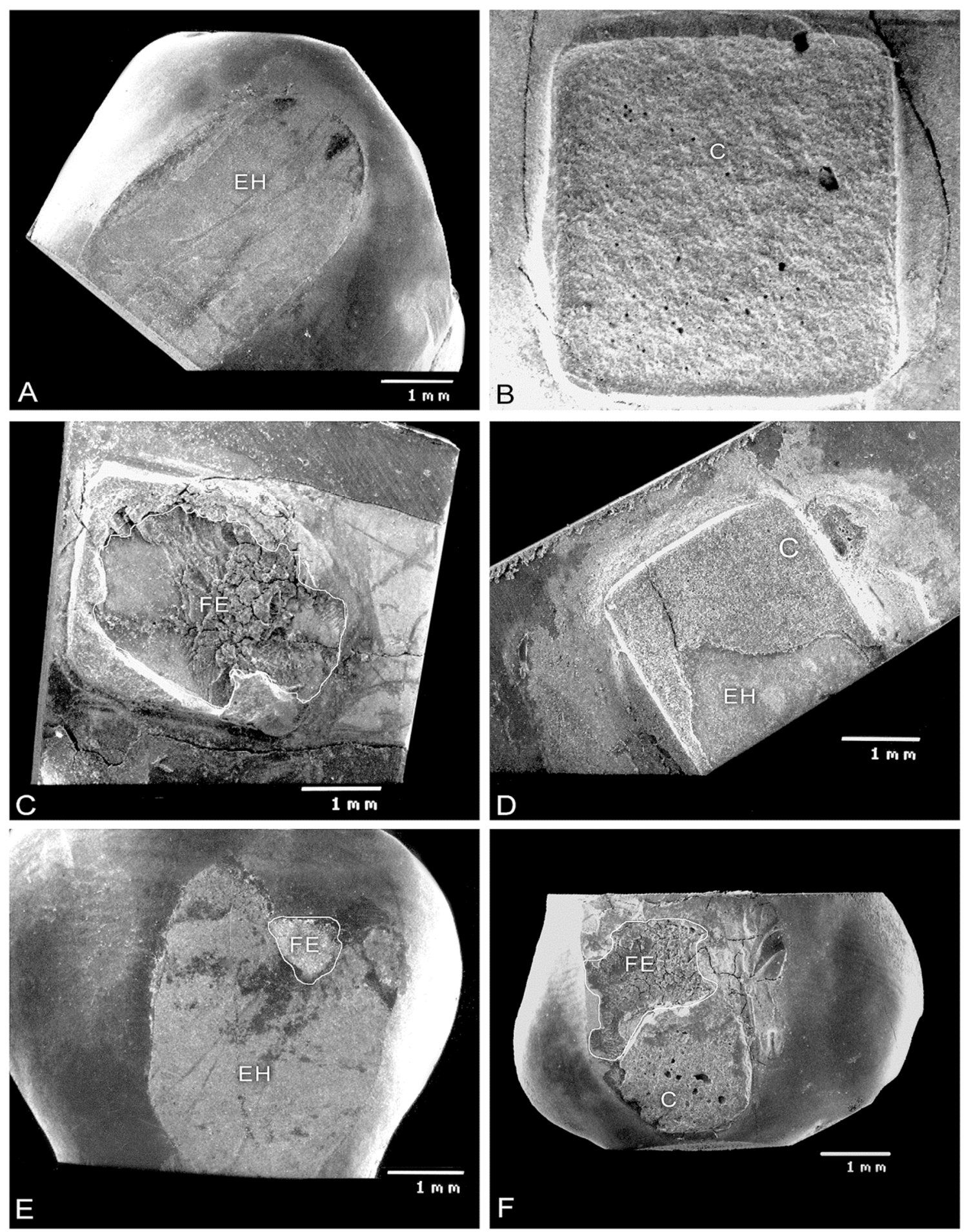

Figura 16 - Tipos de Fratura. A - Fratura Adesiva; B - Fratura Coesiva Resina; C - Fratura Coesiva Esmalte; D - Fratura Mista Coesiva Resina/Adesiva; E - Fratura Mista Coesiva Esmalte/Adesiva; F - Fratura Mista Coesiva Resina/Coesiva Esmalte. EH - Esmalte Hígido. C - Compósito. FE - Fratura de Esmalte. 


\section{Discussão}




\section{DisCUSSÃO}

O laser de Rubi, descoberto por Maiman em 1960, foi o predecessor dos aparelhos de laser utilizados atualmente. Estes equipamentos são os grandes responsáveis por diversos avanços na área médica e odontológica. O uso do laser na Odontologia foi introduzido durante a década de 1980 e início da década de 1990, sendo utilizado para descolagem experimental de bráquetes cerâmicos somente anos depois (Azzeh e Feldon, 2003).

Diversos são os tipos de laser utilizados na odontologia, para a descolagem de bráquetes cerâmicos, entre eles Er:YAG (Oztoprak et al., 2010; Nalbantgil et al., 2010; Tozlu et al., 2011), Nd:YAG (Hayakawa, 2005; Han et al., 2008), laser de Diodo (Feldon et al., 2010), laser de Itérbio (Sarp e Gülsoy, 2010), laser de Argônio (Weinberger et al., 1997) e Tm:YAP (Dostalova et al., 2011). Outro tipo de laser bastante utilizado é o laser de $\mathrm{CO}_{2}$ (Strobl et al., 1992; Rickabaugh et al., 1996; Obata et al., 1999; Iijima et al., 2010; Tehranchi et al., 2010; Ahrari et al., 2011; Macri, 2012; Pessoti et al., 2012) o qual vem apresentando bons resultados, no entanto, o que difere muito entre as pesquisas são os tempos de irradiação e a potência.

Em 1992, Strobl et al. utilizaram o laser de $\mathrm{CO}_{2}$ com potência de $14 \mathrm{~W}$ por 2 segundos, anos mais tarde em 1995, Minura et al. utilizaram as potências de 3 e 7W por tempo não determinado. Rickabaugh et al. (1996) também testaram o laser de $\mathrm{CO}_{2} \mathrm{com}$ potência de 20W sem padronização do tempo. Obata et al., em 1999, testaram o laser de $\mathrm{CO}_{2}$ nas potências de 2 e 3W por um período menor que 4 segundos. Iijima et al., em 2010, testaram o laser de $\mathrm{CO}_{2}$ nas potências de 3, 4, 5 e 6W por 5 segundos e também em 2010 Tehranchi et al., utilizaram a potência de $50 \mathrm{~W}$ por 5 segundos, Ahrari et al. (2011), utilizaram 188W por 5 segundos, Macri (2012) e Pessoti et al., também em 2012, utilizaram a potência de $10 \mathrm{~W}$ por 3 segundos. Essa grande variação da potência e a pouca informação sobre o tempo traz preocupação com relação a problemas de superaquecimento da polpa e a falta de padronização do procedimento. Em nosso estudo, foi utilizado o laser de $\mathrm{CO}_{2} \mathrm{Com}$ potência de $10 \mathrm{~W}$, irradiado por 3 segundos e intervalo de pulso de 0,01 segundo.

Em 1965, Zach e Cohen afirmaram que a polpa dental humana pode suportar variação da temperatura de até $5,5^{\circ} \mathrm{C}$. A preocupação com danos a superfície do esmalte e a polpa decorrentes do aumento da temperatura é comum entre os pesquisadores. Rickabaugh et al. (1996) utilizaram três grupos variando a tensão estática no momento da descolagem sendo utilizadas, 3, 1,5 e 0,75 libras. Os autores encontraram aumento de temperatura intrapulpar de $1,80^{\circ} \mathrm{C}, 3,01^{\circ} \mathrm{C}$ e $4,47^{\circ} \mathrm{C}$, respectivamente, utilizando a potência de 20W. Iijima et al. (2010) avaliaram o efeito da descolagem com laser de $\mathrm{CO}_{2}$ sobre as 
propriedades mecânicas do esmalte e concluíram que embora a irradiação do laser tenha causado grande aumento da temperatura na superfície do esmalte, a dureza e o módulo de elasticidade do mesmo não foram afetadas. Macri (2012) avaliando a temperatura no compósito de colagem e na câmara pulpar após a irradiação com laser de $\mathrm{CO}_{2}$ sob as condições de 10W, por 3 segundos e 0,01 segundo de intervalo de pulso, encontrou que a temperatura do compósito atingiu $101^{\circ} \mathrm{C}$ e da câmara pulpar $4,7^{\circ} \mathrm{C}$. Neste mesmo trabalho, utilizando os mesmos parâmetros citados anteriormente, houve redução significativa na resistência ao cisalhamento dos bráquetes de retenção química Fascination, o que justificou a utilização deste protocolo para nosso estudo.

A resistência adesiva no momento da descolagem do bráquete após a irradiação do laser de $\mathrm{CO}_{2}$ é significativamente menor quando comparado a qualquer outro método de remoção. Por meio de testes de resistência ao cisalhamento autores mediram a força necessária para descolagem de diversos tipos de bráquetes cerâmicos sem irradiação do laser. Bishara et al. (1995), avaliaram a força necessária para remoção de três bráquetes cerâmicos policristalinos de retenção mecânica: Transcend 2000, Transcendo 2000 Precoated e Signature e encontrou variação de 6,6 a 10,1 MPa. No estudo de Theodorakopoulou et al. (2004), a média de resistência ao cisalhamento para o bráquete Clarity foi de 21,67 MPa e para o bráquete Inspire 20,32 MPa. Johnson et al. (2005) encontraram variação de 5,87 a 7,01 MPa para os bráquetes Inspire, Fascination, Mystique, InVu, Clarity, Virage e Luxi. Özcan et al. (2008), compararam as características de resistência ao cisalhamento do bráquete cerâmico Inspire e o bráquete de policarbonato Spirit e encontraram os valores de 11,5 MPa para os cerâmicos e 6,3 MPa para os de policarbonato. Em nosso estudo, os valores para os grupos controles (sem irradiação de laser) foram de 7,63 MPa para os bráquetes Mystique (grupo TMC) e 4,45 MPa para os bráquetes Fascination (grupo TFC). Este resultado está próximo ao encontrado por Bishara et al. (1995) e Johnson et al. (2005), embora discordem dos resultados encontrados por Theodorakopoulou et al. (2004) e Özcan et al. (2008). Esta diferença é consequência da grande quantidade e variedade de bráquetes cerâmicos encontrados no mercado e dos tipos de retenção de suas bases.

No trabalho de Pessoti et al. (2012), que utilizaram os mesmos parâmetros dessa pesquisa (laser de $\mathrm{CO}_{2}, 10 \mathrm{~W}$ e 3 segundos, 0,01 segundo por pulso), foram encontrados resultados semelhantes. Utilizaram dentes bovinos e os bráquetes policristalinos Allure e Transcend de retenção mecânica, divididos em 4 grupos, sendo dois controles e dois experimentais. Os autores encontraram que os valores médios de resistência ao cisalhamento para os grupos controles foram estatisticamente superiores aos encontrados 
nos grupos experimentais (12,22 MPa para o grupo controle do Allure e 0,88 MPa para o grupo experimental do mesmo bráquete e 17,71 MPa para o grupo controle do Transcend e $12,10 \mathrm{MPa}$ para o experimental do mesmo bráquete). Os autores concluíram que a irradiação do laser de $\mathrm{CO}_{2}$ foi capaz de diminuir significativamente os valores de resistência ao cisalhamento dos bráquetes testados.

A redução da força necessária para a descolagem após irradiação do laser de $\mathrm{CO}_{2}$ ficou evidente em nosso estudo que apresentou menores valores de resistência ao cisalhamento para os grupos experimentais. Nos grupos colados com bráquetes Mystique houve redução de mais de 50\% nos valores adesivos quando o laser foi irradiado, independente do compósito utilizado. Redução maior ocorreu com os grupos que utilizaram os bráquetes Fascination que atingiram mais de $90 \%$ no grupo ZFL (Tabela 3, página 46). Esta taxa de diminuição confirma os achados de Pessoti et al. (2012) e não foi encontrada em nenhum outro estudo independente da metodologia empregada. A diminuição da adesão após a irradiação também foi encontrada porém em menor intensidade, nos trabalhos de Strobl et a. (1992), Obata et al., (1999), Tehranchi et al. (2010), Macri (2012). Esse resultado se deve a ação do calor gerado pelo laser que atinge o bráquete e o compósito levando a ruptura de ligações químicas e favorecendo a descolagem.

Wang et al. (1997) avaliaram a descolagem dos bráquetes Fascination e Transcend de retenção química e Lumina e Crystalline de retenção mecânica e encontraram resistência de união significativamente maior para os bráquetes de retenção química. Kitahara-Céia et al. (2008) em estudo in vitro avaliaram danos ao esmalte após a descolagem de bráquetes cerâmicos de retenção mecânica, retenção mecânica com polímero na base e retenção química. Os autores utilizaram microscopia eletrônica de varredura para investigar trincas e fraturas e encontraram que no grupo que utilizou bráquete cerâmico de retenção química houve maior incidência de danos ao esmalte e também maior força para descolagem. Os grupos que utilizaram retenção mecânica se descolaram mais facilmente, além de apresentaram maior quantidade de remanescente adesivo sobre a superfície. Ahrari et al. (2011) avaliaram as características da superfície do esmalte após a descolagem do bráquete cerâmico policristalino Fascination de retenção química e do bráquete cerâmico monocristalino Inspire Ice de retenção mecânica com utilização de laser de $\mathrm{CO}_{2}$ e com alicate. Os autores concluíram que nos grupos controle, descolados com alicate, houve fratura de $45 \%$ dos bráquetes de retenção química e $15 \%$ dos de retenção mecânica e nenhum caso de fratura nos grupos descolados com laser. Estes resultados diferem dos encontrados em nosso experimento onde os maiores valores de resistência ao cisalhamento foram encontrados para os grupos que utilizaram retenção mecânica, embora em nenhum dos grupos testados tenha ocorrido fratura do bráquete no momento da descolagem. Tal 
resultado pode ser explicado ainda pelo fato de serem utilizadas diferentes metodologias com distintas marcas de bráquetes, e até mesmo, variações do laser.

Estudos que avaliaram o modo de fratura indicam a relação entre o tipo de bráquete utilizado, a força necessária para a descolagem e os compósitos utilizados. Rueggeberg e Lockwood (1990) encontraram que para um grupo de 100 bráquetes monocristalinos, colados com compósitos sem mistura utilizando a descolagem térmica, o sítio de fratura se localizou em 4 deles entre o bráquete e a resina (fratura coesiva resina) e em 96 entre o dente e a resina (fratura adesiva). Para o grupo que utilizou os compósitos de colagem com 2 pastas o sítio de fratura se localizou entre o bráquete e a resina (fratura coesiva resina) em 12 dos corpos de prova, entre o dente e a resina (fratura adesiva) em 8 deles e em 60 houve fraturas mistas onde em um mesmo corpo de prova houve fraturas entre o dente e a resina e entre o bráquete e a resina.

Theodorakopoulou et al. (2004) em estudo in vitro avaliaram o modo de fratura após a decolagem do bráquete cerâmico policristalino de retenção mecânica Clarity e o monocristalino também de retenção mecânica Inspire, ambos com alicates. No grupo que utilizou o bráquete Clarity, 17 colagens apresentaram falha na interface bráquete/adesivo caracterizando a fratura coesiva resina e 3 na interface adesivo/esmalte caracterizando a fratura adesiva. No grupo que utilizou o bráquete Inspire, 15 colagens apresentaram falha na interface bráquete/adesivo e 5 na interface adesivo/esmalte. Liu et al. (2005) também avaliaram os bráquetes Clarity e Inspire além de um acessório metálico colados com os compósitos Transbond XT e Enlight e descolados com o auxílio de alicate. Os autores encontraram que o modo de fratura entre os grupos foi predominantemente na interface bráquete/adesivo, caracterizando a fratura coesiva resina. No entanto, os autores relataram também fratura de esmalte (fratura coesiva esmalte) em 2 dos 20 dentes que utilizaram o bráquete Inspire e 1 dos 20 dentes que utilizaram o bráquete Clarity.

Em nosso estudo os corpos de prova submetidos à MEV foram classificados quanto ao modo de fratura e foi encontrado que o tipo de fratura mais prevalente foi a adesiva. Esse resultado está de acordo com Rueggeberg e Lockwood (1990) que em seu estudo encontraram uma prevalência maior de fraturas adesiva, embora discordem dos resultados de Theodorakopoulou et al. (2004) e Liu et al. (2005) que em seus estudos encontraram uma prevalência maior de fraturas coesiva resina.

Em nosso trabalho foram encontrados danos à estrutura dental (fraturas coesivas esmalte e mistas como coesiva resina/coesiva esmalte e coesiva esmalte/adesiva) em 17 dos 109 corpos de prova avaliados, proporção semelhante à encontrada por Liu et al. (2005). O que sugere que as fraturas do esmalte tenham sido consequência do teste de resistência ao 
cisalhamento uma vez que os maiores valores encontrados foram coincidentemente para os corpos de prova que apresentaram danos à superfície dental, tanto nos grupos controle como nos grupos em que houve irradiação com laser.

O tipo de compósito utilizado para a colagem de bráquetes cerâmicos também influencia nos valores de resistência ao cisalhamento. São poucos os estudos encontrados na literatura comparando materiais de colagem e relacionando-os com bráquetes cerâmicos. Mimura et al. (1995) avaliaram o comportamento dos compósitos Concise e Superbond para a colagem de bráquetes cerâmicos e descolagem com laser de $\mathrm{CO}_{2}$ com potência de 3 e 7W. Os resultados demostraram que a força necessária para remover os bráquetes colados com o compósito Superbond foi significantemente menor após a irradiação com laser de $\mathrm{CO}_{2}$. Os autores concluíram ainda que a descolagem com laser de $\mathrm{CO}_{2}$ foi eficaz.

Em nossa pesquisa utilizamos três compósitos para colagem, Transbond XT, Concise Ortodôntico e $Z$ 250. Os resultados encontrados mostram que entre os grupos que utilizaram os mesmos bráquetes os valores de resistência ao cisalhamento não apresentaram diferença estatística (Tabela 3, página 46). Isso nos leva a acreditar que o tipo de material utilizado para a colagem não influenciou nos procedimentos de descolagem. Esse resultado difere do encontrado por Rueggeberg e Lockwood (1990) que avaliaram dez diferentes marcas comerciais de compósitos para colagem de bráquetes, entre eles o compósito Concise, e seus comportamentos frente à descolagem térmica. Concluíram que houve diferenças estatísticas entre os materiais utilizados e que os sistemas de colagens necessitam de diferentes cargas para descolagem, além de diferentes temperaturas. Em 1992, esses mesmos autores avaliaram 23 marcas comerciais, dentre elas Concise e Transbond XT, também utilizado em nosso estudo. Os autores encontraram temperatura média de descolagem de $159^{\circ}$ e $116^{\circ}$ para os compósitos Concise e Tranbond XT, respectivamente. Afirmaram que as diferentes temperaturas necessárias para provocar a descolagem de bráquetes cerâmicos justificam-se devido as composições e apresentações dos materiais de colagem. Vargas (1996), também avaliou diferentes compósitos e encontrou que para o Concise Ortodôntico a temperatura de transição vítrea, ou seja, a temperatura em que o material amolece está em torno $256^{\circ}$ e para o Tranbond XT 3960, embora para facilitar a descolagem os compósitos não necessitam chegar a essa temperatura, o que provavelmente aconteceu em nosso estudo devido à ação do laser.

O Índice de Remanescente Adesivo (IRA) é um método bastante utilizado nas pesquisas para avaliação da superfície do esmalte após a descolagem dos bráquetes. De acordo com a quantidade de adesivo remanescente sobre a superfície dentária após a descolagem pode-se avaliar o modo de fratura e a possibilidade de danos ao esmalte. Quando o modo de fratura ocorre entre o compósito e o dente existe maior possibilidade de 
ocorrência de danos ao esmalte. Quando ocorre na interface bráquete/compósito existe menor possibilidade de danos ao esmalte (Artun e Bergland, 1984).

Kitahara-Céia et al. (2008) avaliaram o IRA para bráquetes de retenção mecânica, retenção mecânica com polímero na base e retenção química. Encontraram melhores resultados para os de retenção mecânica, com 9 espécimes com IRA 3, 5 com IRA 2 e 1 com IRA 1 e piores resultados para os bráquetes com retenção química, sendo 11 com IRA 0, 1 com IRA 1, 1 com IRA 2 e 2 com IRA 3. Em nossa pesquisa, o grupo que apresentou maior média para o IRA, ou seja, maior quantidade de escores 3 foi o ZFL (Z 250 + Fascination + Laser) que utilizou bráquete de retenção química e o grupo que apresentou menor média, maior quantidade de scores 0 , foi o grupo TMC (Transbond XT + Mystique + Controle) que utilizou bráquete de retenção mecânica (Tabela 5, página 47). Embora o resultado não esteja compatível com outros autores, esta diferença pode ser explicada por ser o bráquete de retenção mecânica o que apresentou maior resistência ao cisalhamento. Os demais grupos da nossa pesquisa apresentaram médias do IRA semelhantes entre si. Os resultados demonstram ainda que o valor médio do IRA é inversamente proporcional ao valor médio de resistência adesiva, ou seja, comparando-se as Tabelas 3 (página 46) e 5 (página 47) observamos que o grupo ZFL que obteve maiores valores do IRA obteve menores valores de resistência adesiva, e o grupo TMC que obteve menor média do IRA obteve maior média nos testes de resistência ao cisalhamento. Existem poucos estudos associando essas avaliações, no entanto, o que se observa é que não é possível estabelecer esta relação.

Tehranchi et al. (2010) utilizando bráquete cerâmico policristalino e o compósito quimicamente ativado No-mix, encontraram que a média do IRA para o grupo que utilizou o laser de $\mathrm{CO}_{2}$ como auxiliar na descolagem foi significativamente maior quando comparado ao grupo controle. Resultado semelhante foi encontrado em nossa pesquisa onde a média do IRA nos grupos controle foi menor quando comparado a dos grupos experimentais, com exceção do grupo CFL (Concise + Fascination + Laser) onde a média 0,8 foi inferior aos grupos controle e experimental que utilizaram o mesmo bráquete.

Ahrari et al. (2011) utilizaram o bráquete Fascination de retenção química e o bráquete Inspire Ice de retenção mecânica, ambos descolados com laser de $\mathrm{CO}_{2}$ na potência de $188 \mathrm{~W}$ por 5 segundos. Encontraram maior quantidade de escore 3 para o grupo que utilizou o bráquete de retenção mecânica irradiado com laser seguido pelo grupo controle do mesmo bráquete. Este resultado mais uma vez discorda do encontrado em nossa pesquisa, onde o grupo que apresentou maior quantidade de escore 3 foi o ZFL que utilizou o bráquete de retenção química.

Embora os resultados encontrados na literatura e em nosso trabalho sejam relevantes e indiquem alternativa para contornar os problemas da descolagem de bráquetes cerâmicos, são necessários mais estudos laboratoriais e clínicos para a definição de um protocolo seguro e eficiente. 
Conclusão 


\section{ConclusÃo}

1. A irradiação com laser de $\mathrm{CO}_{2}$ diminuiu os valores de resistência ao cisalhamento da colagem dos bráquetes cerâmicos testados;

2. Os grupos que utilizaram bráquetes cerâmicos de retenção mecânica apresentaram maiores valores de resistência ao cisalhamento;

3. O bráquete cerâmico Fascination, colado com compósito $Z 250$ e irradiado com laser de $\mathrm{CO}_{2}$ foi o que apresentou melhores resultados, ou seja, menores valores de resistência ao cisalhamento, com maior facilidade de remoção, e maior quantidade de remanescente adesivo sobre a superfície dental, com menor ocorrência de danos;

4. As médias do IRA foram maiores para os grupos experimentais (maior quantidade de remanescente adesivo) quando comparados aos controles;

5. Os tipos de fratura encontrados com maior frequência nas MEV's foram as Fraturas Adesivas e Coesiva Resina;

6. Ocorreram fraturas de esmalte em $15 \%$ dos corpos de prova, sendo a maioria delas com o bráquete cerâmico Mystique colado com o compósito Z 250. 
Referências 
REFERÊNCIAS

1. Ahrari F, Heravi F, Fekrazad R, Farzanegan F, Nakhaei S. Does ultra-pulse $\mathrm{CO}_{2}$ laser reduce the risk of enamel damage during debonding of ceramic brackets? Lasers Med Sci. 2012;27:567-74.

2. Anusavice KJ. Phillips materiais dentários. Rio de Janeiro: Elsevier; 2005.

3. Artun J, Bergland S. Clinical trials with crystal growth conditioning as an alternative to acid-etch enamel pretreatment. Am J Orthod. 1984;85:333-40.

4. Azzeh E, Feldon PJ. Laser debonding of ceramic brackets: a comprehensive review. Am J Orthod Dentofacial Orthop. 2003;123:79-83.

5. Bishara SE, Fonseca JM, Boyer DB. The use of debonding pliers in the removal of ceramic brackets: force levels and enamel cracks. Am J Orthod Dentofacial Orthop. 1995; 108:242-8.

6. Bishara SE, Fonseca JM, Fehr DE, Boyer DB. Debonding forces applied to ceramic brackets simulating clinical conditions. Angle Orthod. 1994;64:277-82.

7. Bishara SE, Ostby AW, Laffoon J, Warren JJ. Enamel cracks and ceramic bracket failure during debonding in vitro. Angle Orthod. 2008;78:1078-83.

8. Bishara SE, Thunyaudom T, Chan D. The effect of temperature change of composites on the bonding strength of orthodontic brackets. Am J Orthod Dentofacial Orthop. 1988;94:440-1.

9. Boyer DB, Engelhardt G, Bishara SE. Debonding orthodontic ceramic brackets by ultrasonic instrumentation. Am J Orthod Dentofacial Orthop. 1995;108:262-6.

10. Buonoccore MG. A simple method of increasing the adhesion of acrylic filling materials to enamel surfaces. J Dent Res. 1978;34:849-53.

11. Chevitarese O, Ruellas ACO. Bráquetes ortodônticos: como utilizá-los. São Paulo: Editora Santos; 2005.

12. Cummings $\mathrm{M}$, Biagioni $\mathrm{P}$, Lamey $\mathrm{PJ}$, Burden $\mathrm{DJ}$. Thermal image analysis of electrothermal debonding of ceramic brackets: an in vitro study. Eur J Orthod. 1999;21:111-8.

13. Dostalova $T$, Jelinkova $H$, Sulc J, Nemec $M$, Jelinek $M$, Fibrich $M$, et al. Ceramic bracket debonding by Tm:YAP laser irradiation. Photomed Laser Surg. 2011;29:477-84.

14. Dovgan JS, Walton RE, Bishara SE. Electrothermal debracketing: patient acceptance and effects on the dental pulp. Am J Orthod Dentofacial Orthop. 1995;108:249-55.

15. Feldon PJ, Murray PE, Burch JG, Meister M, Freedman MA. Diode laser debonding of ceramic brackets. Am J Orthod Dentofacial Orthop. 2010;138:458-62. 
16. Han X, Liu X, Bai D, Meng Y, Huang L. Nd:YAG Laser-aided ceramic brackets debonding: Effects on shear bond strength and enamel surface. App Surf Sci. 2008;255:613-15.

17. Hayakawa K. Nd: YAG laser for debonding ceramic orthodontic brackets. Am J Orthod Dentofacial Orthop. 2005;128:638-47.

18. Iijima M, Yasuda $Y$, Muguruma $T$, Mizoguchi I. Effects of $\mathrm{CO}(2)$ laser debonding of a ceramic bracket on the mechanical properties of enamel. Angle Orthod. 2010;80:102935.

19. Jena AK, Duggal $R$, Mehrotra AK. Physical properties and clinical characteristics of ceramic brackets: a comprehensive review. Trends Biomater Artif Organs. 2007;20:20119.

20. Johnson G, Walker MP, Kula K. Fracture strength of ceramic bracket tie wings subjected to tension. Angle Orthod. 2004;75:95-100.

21. Jost-Brinkmann PG, Radlanski RJ, Artun J, Loidl H. Risk of pulp damage due to temperature increase during thermodebonding of ceramic brackets. Eur J Orthod. 1997;19:623-8.

22. Karamouzos A, Athanasiou AE, Papadopoulos MA. Clinical characteristics and properties of ceramic brackets: A comprehensive review. Am J Orthod Dentofacial Orthop. $1997 ; 112: 34-40$.

23. Kearns HP, Sandham JA, Bryan Jones W, Lagerström L. Electrothermal debonding of ceramic brackets: an ex vivo study. BJO. 1997;24:237-42.

24. Kitahara-Céia FM, Mucha JN, Santos PAM. Assessment of enamel damage after removal of ceramic brackets. Am J Orthod Dentofacial Orthop. 2008;134:548-55.

25. Kusy RP. Morphology of polycrystalline alumina brackets and its relationship to fracture toughness and strength. Angle Orthod. 1988;58:197-203.

26. Larmour CJ, Mccabe JF, Gordon PH. An ex vivo investigation into the effects of chemical solvents on the debond behaviour of ceramic orthodontic brackets. BJO. 1998;25:35-9.

27. Liu JK, Chung $\mathrm{CH}$, Chang $\mathrm{CY}$, Shieh DB. Bond strength and debonding characteristics of a new ceramic bracket. Am J Orthod Dentofacial Orthop. 2005;128:761-5.

28. Macri RT. Laser de $\mathrm{CO}_{2}$ como auxiliar na remoção de bráquetes estéticos cerâmicos [tese]. Ribeirão Preto (SP): Faculdade de Odontologia de Ribeirão Preto, Universidade de São Paulo; 2012.

29. Maiman TH. Simulated optical radiation in ruby. Nature. $1960 ; 187: 493-4$.

30. Maltagliati LA, Feres $R$, De Figueiredo MA, Siqueira DF. Bráquetes estéticos considerações clínicas. Rev Clin Ortodon Dental Press. 2006;5:89-95.

31. Mimura H, Deguchi T, Obata A, Yamagishi T, Ito M. Comparison of different bonding materials for laser debonding. Am J Orthod Dentofacial Orthop. 1995;108:267-73. 
32. Nalbantgil D, Oztoprak MO, Tozlu M, Arun T. Effects of different application durations of ER:YAG laser on intrapulpal temperature change during debonding. Lasers Med Sci. 2011;26:735-40.

33. Newman GV. Adhesive and orthodontic plastic attachments. Am J Orthod. 1969;56:57388.

34. Obata A, Tsumura T, Niwa K, Ashizawa Y, Deguchi T, Ito M. Super pulse CO2 laser for bracket bonding and debonding. Eur J Orthod. 1999;21:193-8.

35. Özcan M, Finnema K, Ybema A. Evaluation of failure characteristics and bond strength after ceramic and polycarbonate bracket debonding: effect of bracket base silanization. Eur J Orthod. 2008;30:176-82.

36. Oztoprak MO, Nalbantgil D, Erdem AS, Tozlu M, Arun T. Debonding of ceramic brackets by a new scanning laser method. Am J Orthod Dentofacial Orthop. 2010;138:195-200.

37. Pascotto RC, Hoeppner MG, Pereira SK. Materiais de colagem e cimentação em ortodontia. Parte II - Sistemas adesivos resinosos. R Dental Press Ortodon Ortopedi Facial. 2002;7:115-22.

38. Patel CKN, Mac Farlane RA, Faust WL. Seletive excitation transfer and optical maser action in $\mathrm{N}_{2}-\mathrm{CO}_{2}$. Physiol Rev. 1964;13:617-9.

39. Pessoti G, Galo R, Borsatto MC, Matsumoto MAN, Romano FL. O Laser de $\mathrm{CO}_{2}$ auxilia na descolagem de bráquetes ortodônticos cerâmicos? $20^{\circ}$ SIICUSP; 2012 out 22-26; Ribeirão Preto; 2012.

40. Pinheiro ALB, Brugnera A Jr, Zanin FAA. Aplicação do laser na odontologia. São Paulo: Editora Santos; 2010.

41. Ramos RP. Efeito da irradiação com laser ER:YAG sobre a dentina: avaliação in vitro da resistência a tração de sistemas adesivos convencionais e autocondicionanete em substratos dentinários irradiados, e análise da interface adesiva em MEV [dissertação]. Ribeirão Preto (SP): Faculdade de Odontologia de Ribeirão Preto, Universidade de São Paulo; 2003.

42. Rickabaugh JL, Marangoni RD, McCaffrey KK. Ceramic bracket debonding with the carbon dioxide laser. Am J Orthod Dentofacial Orthop. 1996;110:388-93.

43. Rueggeberg FA, Lockwood PE. Thermal debracketing of orthodontic resins. Am J Orthod Dentofacial Orthop. 1990;98:56-65.

44. Rueggeberg FA, Lockwood PE. Thermal debracketing of single crystal sapphire brackets. Angle Orthod. 1992;62:45-50.

45. Russell JS. Current products and practice aesthetic orthodontic brackets. J Orthod. 2005;32:146-63.

46. Sarp AS, Gülsoy M. Ceramic bracket debonding with ytterbium fiber laser. Lasers Med Sci. 2011;26:577-84. 
47. Scott GE Jr. Fracture toughness and surface cracks--the key to understanding ceramic brackets. Angle Orthod. 1988;58:5-8.

48. Stangler LP. Avaliação da microdureza superficial do esmalte dentário após irradiação com laser de $\mathrm{CO}_{2}$ e aplicação de flúor [monografia]. Ribeirão Preto (SP): Faculdade de Odontologia de Ribeirão Preto, Universidade de São Paulo; 2012.

49. Strobl K, Bahns TL, Willham L, Bishara SE, Stwalley WC. Laser-aided debonding of orthodontic ceramic brackets. Am J Orthod Dentofacial Orthop. 1992;101:152-8.

50. Swartz ML. Ceramic brackets. J Clin Orthod. 1988;22:69-70.

51. Takla PM, Shivapuja PK. Pulpal response in electrothermal debonding. Am J Orthod Dentofacial Orthop. 1995;108:623-9.

52. Tehranchi A, Fekrazad R, Zafar M, Eslami B, Kalhori KA, Gutknecht N. Evaluation of the effects of $\mathrm{CO} 2$ laser on debonding of orthodontics porcelain brackets $v$ s. the conventional method. Lasers Med Sci. 2011;26:563-7.

53. Theodorakopoulou LP, Sadowsky PL, Jacobson A, Lacefield W Jr. Evaluation of the debonding characteristics of 2 ceramic brackets: an in vitro study. Am J Orthod Dentofacial Orthop. 2004;125:329-36.

54. Tozlu M, Oztoprak MO, Arun T. Comparison of shear bond strengths of ceramic brackets after different time lags between lasing and debonding. Lasers Med Sci. 2012;27:11515.

55. Vargas I. Descolagem eletrotérmica de bráquetes cerâmicos colados com diferentes compósitos [dissertação]. Rio de Janeiro (RJ): Universidade Federal do Rio de Janeiro; 1996.

56. Viazis AD, Chabot KA, Kucheria CS. Scanning electron microscope (SEM) evaluation of clinical failures of single crystal ceramic brackets. Am J Orthod Dentofacial Orthop. 1993;103:537-44.

57. Vukovich ME, Wood DP, Daley TD. Heat generated by grinding during removal of ceramic brackets. Am J Orthod Dentofacial Orthop. 1991;99:505-12.

58. Wang WN, Meng CL, Tarng TH. Bond strength: a comparison between chemical coated and mechanical interlock bases of ceramic and metal brackets. Am J Orthod Dentofacial Orthop. 1997;111:374-81.

59. Weinberger SJ, Foley TF, McConnell RJ, Wright GZ. Bond strengths of two ceramic brackets using argon laser, light, and chemically cured resin systems. Angle Orthod. 1997;67:173-8.

60. Winchester $L$. Methods of debonding ceramic brackets. $\mathrm{Br}$ J Orthod. 1992;19:233-7.

61. Zach L, Cohen G. Pulp response to externally applied heat. Oral Sur Oral Med Oral Patho. 1965;19:515-30. 
Anexo 


\section{UNIVERSIDADE DE SÃO PAULO}

Faculdade de Odontologia de Ribeirão Preto

Comitê de Ética em Pesquisa

Of.ATAC.CEP/46611/FORP-USP/21.11.2011

Ref. processo n..$^{\circ} \underline{2011.1 .1014 .58 .0}$

CAAE n. ${ }^{\circ} 0054.0 .138 .000-11$

Senhor(a) Pesquisador(a):

Informamos que o Comitê de Ética em Pesquisa, em sua $125^{a}$ Sessão, realizada em 17 de novembro de 2011, aprovou o desenvolvimento do projeto de pesquisa envolvendo seres humanos, intitulado "Resistência ao cisalhamento de bráquetes ortodónticos cerâmicos colados com diferentes compósitos irradiados com laser de CO2".

$\mathrm{Na}$ oportunidade, lembramos da necessidade de serem entregues, na secretaria do CEP, o Relatório Parcial em 17 de setembro de 2012 e o Relatório Final em 17 de julho de 2013, com os respectivos formulários preenchidos pelo pesquisador responsável.

Lembramos ainda que, quando da submissáo do relatório a este Comitê, quaisquer inclusర̌es ou modificaçס̌es no projeto original deverăo ser comunicadas e justificadas ao CEP, através do formulário supracitado.

\section{Gdactd \\ GISELE ELLENE DE ANDRADE DA DALTI \\ Secretária do Comitê de Ética em Pesquisa}

IImo(a). Sr(a).

PROF. DR. FÁBIO LOURENÇO ROMANO

Departamento de Clinica Infantil, Odonologia Preventiva e Social

desta Faculdade 